\title{
Full-scale CFD simulation of tsunamis. Part 1: Model validation and run-up
}

\section{Larsen, Bjarke Eltard; Fuhrman, David R.}

\section{Published in:}

Coastal Engineering

Link to article, DOI:

10.1016/j.coastaleng.2019.04.012

Publication date:

2019

Document Version

Peer reviewed version

Link back to DTU Orbit

\section{Citation (APA):}

Larsen, B. E., \& Fuhrman, D. R. (2019). Full-scale CFD simulation of tsunamis. Part 1: Model validation and runup. Coastal Engineering, 151, 22-41. https://doi.org/10.1016/j.coastaleng.2019.04.012

\section{General rights}

Copyright and moral rights for the publications made accessible in the public portal are retained by the authors and/or other copyright owners and it is a condition of accessing publications that users recognise and abide by the legal requirements associated with these rights.

- Users may download and print one copy of any publication from the public portal for the purpose of private study or research.

- You may not further distribute the material or use it for any profit-making activity or commercial gain

- You may freely distribute the URL identifying the publication in the public portal

If you believe that this document breaches copyright please contact us providing details, and we will remove access to the work immediately and investigate your claim 


\title{
Full-scale CFD simulation of tsunamis. Part 1: Model validation and run-up
}

\author{
Bjarke Eltard Larsen ${ }^{\mathrm{a}, *}$, David R. Fuhrman ${ }^{\mathrm{a}}$ \\ ${ }^{a}$ Technical University of Denmark, Department of Mechanical Engineering, Section of \\ Fluid Mechanics, Coastal and Maritime Engineering, DK-2800 Kgs. Lyngby, Denmark
}

\begin{abstract}
This paper presents numerical simulations of the propagation, shoaling and run-up of full-scale tsunami waves. The simulations are performed with a model solving Reynolds-averaged Navier-Stokes equations with $k$ - $\omega$ turbulence closure, and is one of very few studies involving CFD simulations at full tsunami scale, involving full resolution of small scale dispersive effects as well as wave breaking. It is demonstrated that a combination of previous analytical and empirical expressions for run-up heights and inundation speeds match those simulated well. This indicates that these are reasonable first approximation even in cases where the underlying assumption of linearity of the incoming tsunami is violated, as well as in cases where breaking occurs, though they generally slightly underestimate both run-up height and inundation speed. It is shown that the run-up of tsunamis can manifest in different ways depending on the initial wave shape and slope of the coast, and three qualitative run-up types previously identified in the literature are described in detail. It is further shown that the shorter waves of an undular bore, which appear during lengthy propagation in shallow water, can either maintain their shape the entire distance to shore, or break far offshore creating a breaking bore. It is demonstrated the front of the breaking bore will not appear as steep for $\mathrm{N}$-waves as single waves because these need to re-wet the drawn-down region before reaching the original shoreline. Finally, the importance of shorter waves riding on the front of the tsunami is discussed. It is shown that they have little impact on the run-up height and inundation speed, but are important in terms of local flow velocities. The results presented here are Part 1 of a larger study, where Part 2 involves details of the tsunami-induced boundary layer dynamics, bed shear stresses
\end{abstract}

\footnotetext{
* Corresponding author

Email address: bjelt@mek.dtu.dk (Bjarke Eltard Larsen)
} 
and implication for sediment transport.

Keywords: Tsunamis, Computational Fluid Dynamics, Run-up, inundation, RANS, Turbulence modelling

\section{Introduction}

When tsunamis hit a coast they are potentially catastrophic as seen in the two recent major tsunami incidents, the Boxing day tsunami in 2004 in the Indian Ocean, and the Tohoku tsunami in Japan in 2011 where approximately 230,000 and 20,000 people were killed, respectively (Suppasri et al., 2012). These tsunamis also caused severe damage to buildings and structures, and in many places houses and bridges were washed away. With the destructive force of the tsunamis, run-up and inundation have naturally received considerable attention in the past.

Experimentally, however, the run-up of tsunami waves is difficult to study due to the scales involved, even at model scale with a large scaling factor. Jiang et al. (2015) boldly stated that: "both the length and time scales of an actual tsunami wave cannot be down-scaled in wave flume experiments according to the Froude similarity law." A similar point was made by Chen et al. (2012). As a result many have used solitary or other short wave forms, which might be interesting in themselves (and useful e.g. for model validation), but their resemblance to geophysical tsunamis is at best questionable (Madsen et al., 2008).

Despite the challenges mentioned above a limited number of studies have been made where reasonable scaling was achieved, using large scale facilities. Matsuyama et al. (2007) did a properly scaled tsunami experiment in their $200 \mathrm{~m}$ long wave flume. Their waves were sinusoidal and ran up different bathymetries. While propagating, the waves developed into undular bores which shoaled, and the individual short waves ultimately broke. They did not focus on run-up height, but rather on wave transformation, wave breaking and velocities during breaking. To our knowledge this is the first experiment of its sort where undular bores showed up in an experimental study involving the run-up of tsunamis. Recently Schimmels et al. (2016) and Sriram et al. (2016) generated properly scaled tsunami waves with a piston wave-maker. The waves propagated on a flat bed, before running up a 1/6 slope. Here the run-up heights were not measured, but they demonstrated the splitting of the wave front into an undular bore, similar to Matsuyama et al. (2007), and they also showed the reflected wave. Others have achieved reasonable scaling using other generation methods, see e.g. 
the pump generated tsunami experiments by Rossetto et al. (2011), Goseberg et al. (2013), Goseberg (2013), Drähne et al. (2016) and Larsen et al. (2018a).

The run-up of tsunamis has also been studied numerically, often using either non-linear shallow water (NLSW) or Boussinesq models. For good reviews of NLSW models applied on tsunamis, the reader is referred to Synolakis and Bernard (2006) and Levin and Nosov (2016). Despite not being able to handle dispersion NLSW models have, as stated by Madsen et al. (2016), had reasonable success in simulating geophysical tsunamis. Over long propagation distances however, a dispersive tail might evolve, and when the undular bores form in shallow water dispersion likewise becomes important. (For a more in depth discussion on the role of dispersion for tsunami waves please see Grue et al. (2008), Kim and Lynett (2011), Glimsdal et al. (2013), Løvholt et al. (2012), Grilli et al. (2013).) Dispersion can obviously be handled by Boussinesq type models (see e.g Lynett and Liu (2002), Lynett and Liu (2005) and Fuhrman and Madsen (2009)), but such models are limited to a single-valued free surface and still require an empirical breaking model.

Computational Fluid Dynamics (CFD) models, on the contrary, can in principal handle both non-linearity and dispersion, and in contrast to NLSW and Boussinesq models, actually resolve breaking and bottom boundary layer processes directly. CFD studies of tsunamis are few, however, due to their computational expense. Horrillo et al. (2006) simulated the propagation of the Indian Ocean tsunami using both a NLSW model, a Boussinesq model and a Reynolds-averaged Navier-Stokes (RANS) model and concluded that over long propagation distances dispersion became important, which only the Boussinesq and CFD model could describe. Horrillo et al. (2006) did not go into details regarding the simulated run-up with the CFD model, however. Biscarini (2010) first validated their CFD model against an experimental landslide-generated tsunami, and was subsequently able to accurately predict the run-up height of the 1958 Lituya Bay (Alaska) landslide-generated tsunami. Montagna et al. (2011) validated their CFD model (Flow 3D) with an experimental landslide generated tsunami and concluded that the model was able to accurately reproduce surface elevations near the generation as well as in inundated areas, but did not proceed to simulate full-scale tsunami events. Tomita and Takahashi (2014) used the STOC-IC model, developed by Tomita et al. (2006), and were able to accurately reproduce an experiment where undular bores showed up at the tsunami wave front. The STOC-IC model, however, is not a standard CFD model, as the surface elevation is solved for using a depth-averaged con- 
tinuity equation. This mean that this type of model cannot handle the overturning of the breaking waves as well as the mixture of air and water that occur e.g. in the front of a breaking bore. Qu et al. (2017) compared run-up heights of properly scaled tsunamis with those obtained using a solitary wave. Similar to Madsen et al. (2008) they concluded, that there were great differences between solitary waves and properly scaled tsunami waves. Finally, Aniel-Quiroga et al. (2018a) used a hybrid approach, coupling a NLSW model for the initial propagation with a RANS model for the runup, to simulate the run-up of tsunamis for a wide range of topographies and initial tsunami waves. Based on these they created an interpolation model which could output the run-up height for different input topographies and wave shapes. They showed that this approach compared reasonably well with past measured tsunami run-up heights. For a more in-depth review of tsunami literature focusing on propagation and run-up please see the $\mathrm{PhD}$ thesis by Larsen (2018).

Despite the large number of studies on tsunami run-up, the process is still not fully understood in detail. In this work we will use CFD to study and clarify how tsunamis run-up in different scenarios, both in terms of runup height, inundation speed as well as a more qualitative description of the run-up sequence. With the latter we intend to focus on the various ways tsunamis can appear at the coast. Often in experiments a breaking bore is assumed either generated through dam breaks (see e.g. Yeh, 1991; Derschum et al., 2018; Stolle et al., 2018) or as a result of breaking elongated solitary waves (see e.g. Goseberg et al., 2016; Nistor et al., 2017), but a tsunami can run-up in other ways as well. We wish to characterise these scenarios and describe when they appear. Finally, as the CFD model naturally handles dispersion and resolves the breaking process directly, this study also aims to investigate the quantitative importance of shorter dispersive waves, sometimes appearing at the tsunami wave front, on both the run-up, inundation speed and local flow velocities. The generated knowledge can potentially be important for hazard assessment by describing run-up heights and inundation speeds for different scenarios, as well as design of experimental campaigns (as it can help identify more appropriate run-up scenarios).

The simulations presented in the present paper are also used in Larsen and Fuhrman (2018a) (hereafter referred to as Part 2). Here details of the tsunami-induced boundary layer dynamics, bed shear stresses and implications for sediment transport are discussed.

The remainder of the study is organized as follows: Model description and boundary conditions are given in Section 2. In Section 3 the model is validated first for the propagation of long non-linear waves over large 
distances by comparing with results from Sriram et al. (2016), and then for its performance on surface elevations and bed shear stresses in the surf and swash zone by comparing to measurements of Sumer et al. (2011). In Section 4 the case selection and model setup is described. Section 5 shows the model results for run-up heights and inundation speed of two archetype tsunami signals using different slopes. Section 6 entails a detailed description of different run-up types, and in Section 7 a discussion of when the different run-up types appear is performed. Finally, in section 8 overall conclusions are drawn.

\section{Model description}

The simulations are performed using the two-phase volume-of-fluid method (VOF) flow model waves2FOAM developed by Jacobsen et al. (2012). Here the Reynolds-averaged Navier-Stokes (RANS) (1) and continuity (2) equations are solved:

$$
\begin{gathered}
\frac{\partial \rho u_{i}}{\partial t}+u_{j} \frac{\partial \rho u_{i}}{\partial x_{j}}=-\frac{\partial p^{*}}{\partial x_{i}}-g_{j} x_{j} \frac{\partial \rho}{\partial x_{i}}+\frac{\partial}{\partial x_{j}}\left(2 \mu S_{j i}+\tau_{i j}\right), \\
\frac{\partial u_{i}}{\partial x_{i}}=0 .
\end{gathered}
$$

Here $u_{i}$ are the ensemble averaged components of the velocities, $x_{i}$ are the Cartesian coordinates, $\mu=\rho \nu$ is the dynamic molecular viscosity, $\nu$ is the kinematic viscosity, $\rho$ is the density, $p^{*}$ is the pressure in excess of hydrostatic, $t$ is time, $S_{i j}$ is the mean strain rate tensor given by

$$
S_{i j}=\frac{1}{2}\left(\frac{\partial u_{i}}{\partial x_{j}}+\frac{\partial u_{j}}{\partial x_{i}}\right),
$$

and $\tau_{i j}$ is the Reynolds stress tensor, which is expressed according to the Boussinesq approximation

$$
\frac{\tau_{i j}}{\rho}=-\overline{u_{i}^{\prime} u_{j}^{\prime}}=2 \nu_{T} S_{i j}-\frac{2}{3} k \delta_{i j}
$$

Here the overbar signifies time (ensemble) averaging, $\nu_{T}$ is the eddy viscosity, $\delta_{i j}$ is the Kronecker delta, and

$$
k=\frac{1}{2} \overline{u_{i}^{\prime} u_{i}^{\prime}}
$$




$$
P_{b}=-\frac{g_{i}}{\rho} \overline{\rho^{\prime} u_{i}^{\prime}}=p_{b} \nu_{T}, \quad p_{b}=\alpha_{b}^{*} N^{2}, \quad N^{2}=\frac{g_{i}}{\rho} \frac{\partial \rho}{\partial x_{i}},
$$

144 where $\left(g_{1}, g_{2}, g_{3}\right)=(0,0,-g)$ is gravitational acceleration and $N^{2}$ is the 145 square of the Brunt-Vaisala frequency. The production of $\omega$ is likewise taken 146 as

$$
P_{\omega}=\alpha \frac{\omega}{k} \frac{\tilde{\omega}}{\tilde{\tilde{\omega}}} P_{k}=\alpha \frac{\omega}{\tilde{\tilde{\omega}}} p_{0} .
$$

147 In this model the eddy viscosity is defined as

$$
\nu_{T}=\frac{k}{\tilde{\omega}}
$$

148 with

$$
\tilde{\tilde{\omega}}=\max \left[\omega, \lambda_{1} \sqrt{\frac{p_{0}-p_{b}}{\beta^{*}}}\right],
$$




$$
\tilde{\omega}=\max \left[\tilde{\tilde{\omega}}, \lambda_{2} \frac{\beta}{\beta^{*} \alpha} \frac{p_{0}}{p_{\Omega}} \omega\right] .
$$

The formulation of the Larsen and Fuhrman (2018b) $k$ - $\omega$ model above was designed to maintain stability in potential flow regions, while defaulting to a standard closure in sheared regions. Mayer and Madsen (2000) showed that two-equation closure models could be unstable in the potential flow region beneath surface waves, resulting in exponential growth of the turbulent kinetic energy and eddy viscosity, leading to wide-spread over production of turbulence in the literature (see e.g the recent state-of-the art applications of Brown et al. (2016)). As shown by Larsen and Fuhrman (2018b), the inclusion of the two stress limited versions of $\omega$ (i.e. $\tilde{\omega}$ and $\tilde{\tilde{\omega}}$ ) arranged as above, formally solves this wide-spread and long-standing problem.

The standard closure coefficients utilized are those of Wilcox (2006): $\alpha=0.52, \beta=0.0708$ (constant for $2 \mathrm{D}$ flows), $\beta^{*}=0.09, \sigma=0.5, \sigma^{*}=0.6$, $\sigma_{d o}=0.125$, with

$$
\sigma_{d}=H\left(\frac{\partial k}{\partial x_{j}} \frac{\partial \omega}{\partial x_{j}}\right) \sigma_{d o},
$$

where $H(\cdot)$ is the Heaviside step function, which takes a value of unity if the argument is positive and zero otherwise. Additionally, we adopt the value $\alpha_{b}^{*}=1.36$, which was derived by Larsen and Fuhrman (2018b), as well as the stress limiting coefficients $\lambda_{1}=0.2$ and $\lambda_{2}=0.05$.

A scalar field $\gamma$ is used to track the two fluids, where $\gamma=0$ represents pure air and $\gamma=1$ pure water, with any intermediate value representing a mixture. The distribution of $\gamma$ is governed by the advection equation

$$
\frac{\partial \gamma}{\partial t}+u_{j} \frac{\partial u_{i} \gamma}{\partial x_{j}}+u_{j}^{r} \frac{\partial u_{i}^{r} \gamma(1-\gamma)}{\partial u_{j}^{r}}=0
$$

where $u_{j}^{r}$ is a relative velocity used to compress the interface. The method is developed by OpenCFD, and it is documented in Berberovic et al. (2009). Any fluid property $\Phi$ in the flow is assumed to be given by

$$
\Phi=\gamma \Phi_{\text {water }}+(1-\gamma) \Phi_{\text {air }}
$$

The boundary conditions are as follows: The bottom will have a noslip condition imposed such that velocities are zero. For the turbulence quantities at the bottom a generalized wall function approach is used. The friction velocity is determined from the tangential velocity at the nearest 
cell center, based on the profile of Cebeci and Chang (1978):

$$
\begin{gathered}
\frac{u}{U_{f}}=2 \int_{0}^{y_{c}^{+}} \frac{d y^{+}}{1+\left[1+4 \kappa^{2}\left(y^{+}+\Delta y_{c c}^{+}\right)^{2} C\right]^{1 / 2}}, \\
C=\left[1-\exp \left(-\left(y^{+}+\Delta y_{c c}^{+}\right) / 25\right)\right]^{2}, \\
\Delta y_{c c}^{+}=0.9\left[\sqrt{k_{s}^{+}}-k_{s}^{+} \exp \left(-\frac{k_{s}^{+}}{6}\right)\right],
\end{gathered}
$$

who generalized the van Driest (1956) profile to incorporate potential roughness effects, with $y_{c}=\Delta y / 2$ being the normal distance from the wall to the nearest cell center, where $\Delta y$ is the thickness of the near wall cell, $k_{s}=2.5 d$ is Nikuradse's equivalent sand roughness and $y_{c}^{+}=y_{c} U_{f} / \nu$. The boundary conditions for $k$ and $\omega$ are then as described by Fuhrman et al. (2014)

$$
\begin{gathered}
\frac{k}{U_{f}^{2}}=\min \left\{A y_{c}^{+2}, \frac{1}{\sqrt{\beta^{*}}}\right\}, \\
\frac{\omega \nu}{U_{f}^{2}}=\max \left\{\frac{B}{y_{c}^{+2}}, \frac{1}{\sqrt{\beta^{*}} \kappa y_{c}^{+}}\right\} .
\end{gathered}
$$

The first arguments in these functions ensure that these variables follow their proper scaling $k \sim y^{2}$ and $\omega \sim 1 / y^{2}$ for near wall cells within the viscous sublayer (see e.g. Wilcox $(2006))$. The values $A=1 /\left(\delta^{+2} \sqrt{\beta^{*}}\right)=0.02466$ and $B=\delta^{+} /\left(\sqrt{\beta^{*}} \kappa\right)=96.885$ are utilized, which ensure a continuous transition to the (fully-turbulent) second arguments at $y_{c}^{+}=\delta^{+}$, where $\delta^{+}=11.626$ is taken as the viscous sub-layer thickness (in dimensionless wall coordinates). In the first cells nearest the bed, the eddy viscosity is not calculated from (11), but is instead calculated from

$$
U_{f}^{2}=\frac{\tau_{b}}{\rho}=\left(\nu+\nu_{T}\right) \frac{d U}{d z} .
$$

The wall functions described above have been used previously to a great extent, see e.g. Baykal et al. (2015), Larsen et al. (2016), Bayraktar et al. (2016) and Larsen and Fuhrman (2018b).

The tsunami waves in this study, will be specified either as initial conditions or generated at the inlet. Specifically these will be represented by a general $\mathrm{N}$-wave form (the summation of a positive and negative single wave) inspired by Madsen and Schäffer (2010), but with $x$ variation now included. The free-surface is given by 


$$
\begin{aligned}
\eta(x, t) & =A_{1} \operatorname{sech}\left[\Omega_{1}\left(\left(t-t_{1}\right)-\frac{x-x_{0}}{\sqrt{g h}}\right)\right]^{2} \\
& -A_{2} \operatorname{sech}\left[\Omega_{2}\left(\left(t-t_{2}\right)-\frac{x-x_{0}}{\sqrt{g h}}\right)\right]^{2}
\end{aligned}
$$

where $A_{1}$ and $A_{2}$ are the amplitudes of the two single waves, the effective frequencies $\Omega_{1}$ and $\Omega_{2}$ define the time span of the two single waves according to $\Omega_{i}=2 \pi / T_{i}$ where $T_{i}$ can be interpreted as the effective period of the corresponding single wave, defined as the time separating where the surface elevations drops below $0.7 \%$ of the amplitude. The variable $x_{0}$ defines the center of the wave and $t_{1}$ and $t_{2}$ can be used to phase shift the two single waves. This signal can be reduced to a single (direction) wave by setting $A_{2}=0$. Please note that this formulation is different than the solitary wave as the period and wave height can be chosen independently. The solitary wave can be viewed as a special case of the single wave with $\Omega_{1}=\sqrt{3 g A_{1} /(4 h)}$. The horizontal velocity is then given based on linear shallow water theory

$$
u(x, t)=\sqrt{\frac{g}{h}} \eta(x, t)
$$

The vertical velocity is derived from the local continuity equation, and the pressure is calculated as hydrostatic.

\section{Model validation}

Before simulating the actual tsunami-scale events it is important to validate that the model can, in fact, handle the necessary and relevant physics. Therefore it will be shown that the model is capable of handling the propagation and wave deformation of long waves over long distances. It will likewise be shown that the model can handle potential breaking of short waves as well as run-up in situations where breaking occurs.

\subsection{Long wave propagation over long distances}

In this section the model results are compared to one of the experiments of Sriram et al. (2016). Sriram et al. (2016) investigated how long waves with different shapes and amplitudes propagated on a flat bed and subsequently ran up a steep slope of $S=1 / 6$. The model will be compared to the test named " $2 / 3$ " by Sriram et al. (2016). The incoming wave was a single wave (hence $A_{2}=0$ ), with a period $T=30 \mathrm{~s}$, and an amplitude $A_{1}=$ 


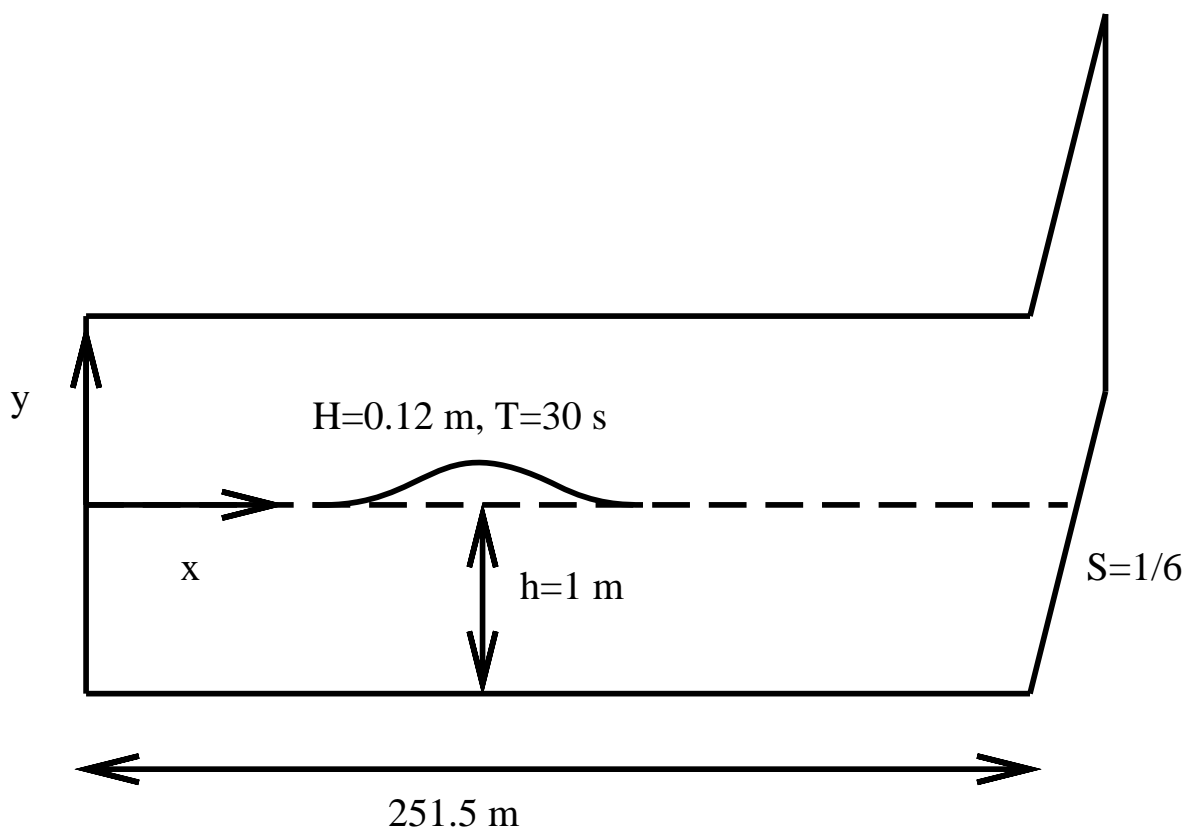

Figure 1: Layout of the computational domain for the Sriram et al. (2016) experiment. Note that this sketch is not to scale.

$0.12 \mathrm{~m}$ at a water depth $h=1 \mathrm{~m}$. This wave signal was used as an inlet condition with the inlet of the flume positioned at $x=0 \mathrm{~m}$ and the toe of the slope at $x=251.5 \mathrm{~m}$. Figure 1 shows a sketch of the domain used in the simulations. The mesh in the majority of the domain has a height of $\Delta y=0.01 \mathrm{~m}$ and $\Delta x=0.02 \mathrm{~m}$. This means that 12 cells are used to discretize the amplitude. This was shown by Larsen et al. (2018b) to be a reasonable resolution for propagating waves. All forthcoming simulations will have at least this number of cells per wave amplitude and keep the same aspect ratio, $\Delta x / \Delta y$. Near the bed the cells were gradually refined in the vertical, with near bed cells having $\Delta y=6 \cdot 10^{-4} \mathrm{~m}$. In this and all future simulations the time step was adjusted such that a maximum Courant number $C o=\left|u_{i}\right| \Delta t / \Delta x_{i}=0.15$ is maintained at all times. This is lower than used in most CFD studies, but a low Courant number was shown by Larsen et al. (2018b) to be necessary to accurately simulate free surface waves with the interFOAM solver.

Figure 2 shows the modelled and experimental surface elevations at two 

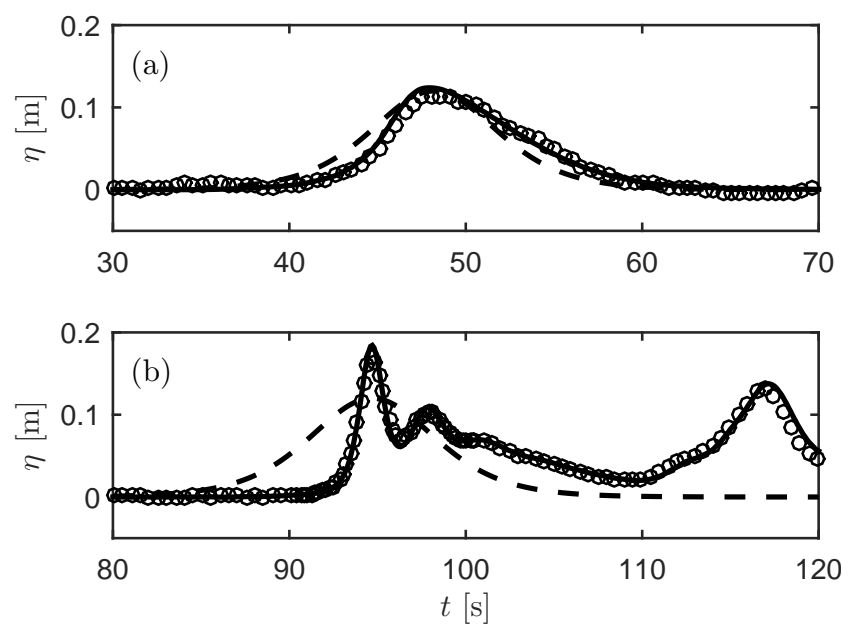

Figure 2: Comparison between modelled (-) and experimental (o) from Sriram et al. (2016) surface elevations at (a) $x=60 \mathrm{~m}$ and (b) $x=225 \mathrm{~m}$. Included in the figures is also the initial time-shifted single wave $(--)$ to illustrate how the wave deforms while propagating.

different locations in the flume. Included for comparison as a dashed line is also the initial analytical single wave expression (see again (23)), with the peak shifted to match the experiments. It can be seen that at $x=60$ $\mathrm{m}$ (Figure 2a) the wave has deformed slightly, now having a steeper wave front, compared to the single wave expression. At $x=225 \mathrm{~m}$ (Figure 2b) the wave is starting to split and two clear peaks are visible. The third peak in Figure $2 \mathrm{~b}$ (at approximately $t=117 \mathrm{~s}$ ) is the reflected wave. In general the comparison between the CFD model and the experiment is good. The root mean squared errors (RMSE) between the experiments and the model are $\mathrm{RMSE}=0.005 \mathrm{~m}$ and $\mathrm{RMSE}=0.006 \mathrm{~m}$ (i.e. approximately half the thickness of a cell) at $x=60 \mathrm{~m}$ and at $x=225 \mathrm{~m}$ respectively. The model captures both the initial deformation of the wave (Figure 2a) and the subsequent split and reflection (Figure $2 \mathrm{~b}$ ). This shows that the model, with the present mesh resolution, is capable of handling both dispersion and non-linearity. That the model is able to capture the reflection accurately also suggests that it is capable of handling the run-up and run-down of a non-breaking long single wave accurately.

\subsection{Surface elevations and bed shear stresses in the surf and swash zone}

Having shown that the model can handle propagation, deformation and reflection of long waves, we will now validate that the model can handle the more complex surf and swash zone. The model will therefore be compared 


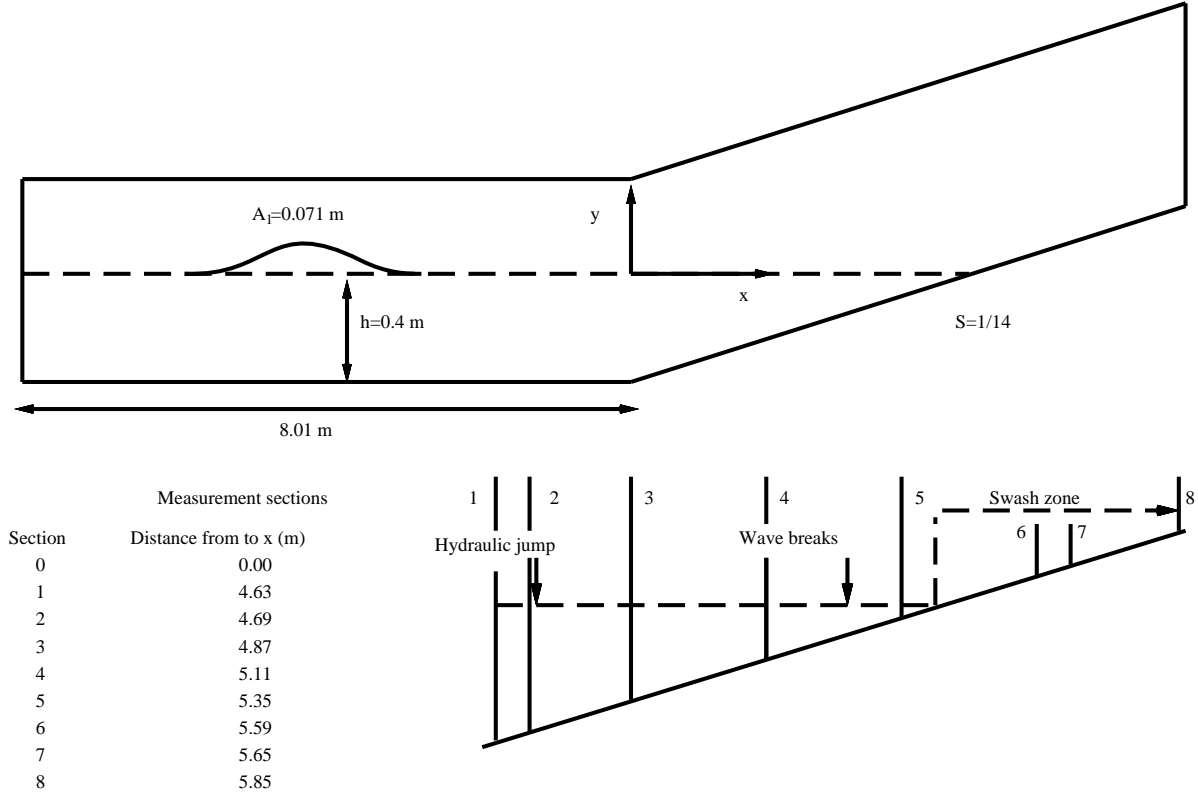

Figure 3: Layout of the computational domain and positions of the measurement sections for the Sumer et al. (2011) experiment. Note that this sketch is not to scale.

with experimental results involving a plunging solitary wave by Sumer et al. (2011). Here a solitary wave with amplitude $A_{1}=0.071 \mathrm{~m}$ was generated on a water depth $h=0.4 \mathrm{~m}$. As mentioned, the solitary wave can be viewed as a special case of the single wave with $\Omega_{1}=\sqrt{3 g A_{1} /(4 h)}$. In the experiments, the wave propagated on a flat bed which was $8.01 \mathrm{~m}$ long, before continuing up a slope of $S \approx 1 / 14$. Surface elevations were measured with wave gauges at nine different cross-shore positions, and bed shear stresses were measured with hot film at eight different cross shore positions. The toe of the slope is positioned at $x=0 \mathrm{~m}$. The layout of the computational domain, as well as the measurement positions (with the exception of section 0 , which is positioned at the toe of the slope) are shown in Figure 3. The majority of the domain is discretized into cells having a size of $\Delta y=0.005 \mathrm{~m}$ and $\Delta x=0.01$ $\mathrm{m}$, which corresponds to approximately 14 cells per wave amplitude, and an aspect ratio of $\Delta x / \Delta y=2$. This is a very similar resolution as in the previous validation case. The approximate same number of cells per wave height has also shown to work well for breaking waves in Larsen and Fuhrman (2018b). For the bottom $0.05 \mathrm{~m}$ the grid is gradually refined in the vertical 
over 21 cells with near bed cells having $\Delta y=6 \cdot 10^{-4} \mathrm{~m}$ (this resolution gives 8 cells for the bottom $0.01 \mathrm{~m}$ ). A solitary wave is initialized in the domain with the crest of the wave positioned at $x=-4.5 \mathrm{~m}$.

Figure 4 shows a sequence of the computed breaking and run-up of the solitary wave. In Figure 4a,b, a clear plunger is seen, with a small pocket of air trapped beneath the plunging wave (Figure $4 \mathrm{~b}$ ). In Figure $4 \mathrm{c}$ the wave is at the maximum run-up height. In Figure $4 \mathrm{~d}$ a hydraulic jump is forming as the wave is drawing down. This hydraulic jump travels seaward as shown in Figure $4 \mathrm{e}$, and a complicated air-water mixture is seen just seaward of the hydraulic jump. Finally, in Figure $4 \mathrm{f}$ a trailing wave, involving a mixture of air and water can be seen. Qualitatively, the sequence presented here is very similar to sketch in Figure 2 of Sumer et al. (2011), describing the sequence of breaking, run-up and draw-down.

Figure 5 shows the comparison between the experimental and modelled surface elevations at five different cross shore positions. It can be seen that the model is capable of capturing the surface elevation at the toe (Figure 5a), in the shoaling region (Figure 5b-c), in the surf zone (Figure 5d) and in the swash zone (Figure 5e). The largest discrepancy is found at section 1 during the run-down (Figure $5 \mathrm{~b}$ at $t=8-12 \mathrm{~s}$ ). The reason for this discrepancy is probably that the hydraulic jump forms just onshore of the measurement position at this time and move seaward, as seen in Figure 4d,e. The hydraulic jump in the experiments occurred at this position (see Figure 2 in Sumer et al. (2011)), but it seems that there are discrepancies in the measured and computed surface elevations. These may be due to the model not resolving the complex hydraulic jump well enough, but it may also be due to difficulties in clearly defining a free-surface position in this complex region. In this situation there is a complex mixture of air and water as illustrated in the sketch in figure 2 from Sumer et al. (2011) as well as Figure 4b. In the experiments the free-surface was determined using resistive wave gauges. These are calibrated in pure water, and therefore it is questionable exactly which position is given in this situation with air mixture. In the model the surface elevations is found from the $\gamma=0.5$ iso-line but in reality it span a minimum of two cells. 

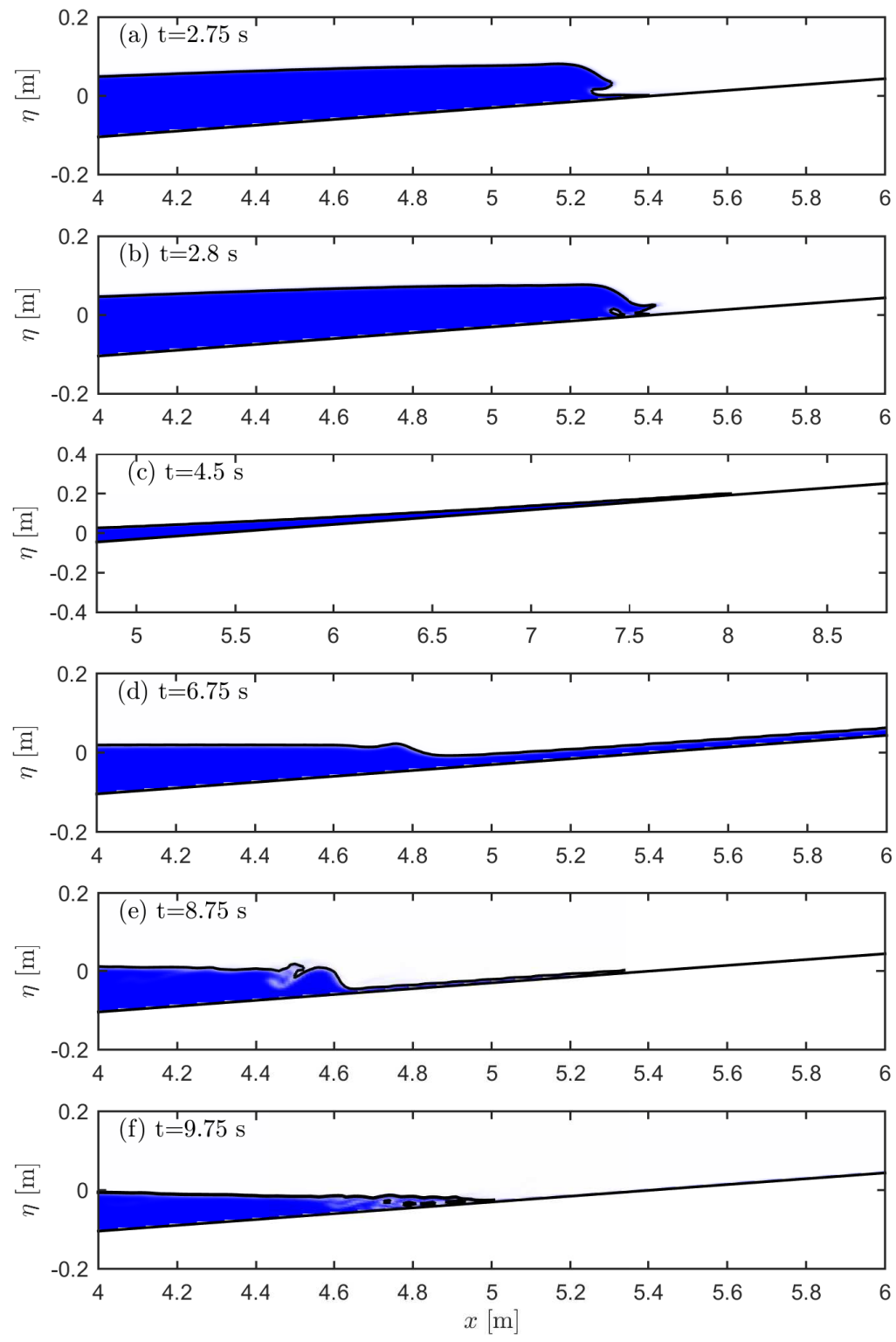

Figure 4: Sequence of the run-up of the solitary wave. The wave can be seen plunging in (a),(b), at full run-up height in (c), the initialization of the hydraulic jump in (d), the hydraulic jump moving seawards in (e) and the trailing wave in (f). Note that the axis in (c) is different from the other subplots. 

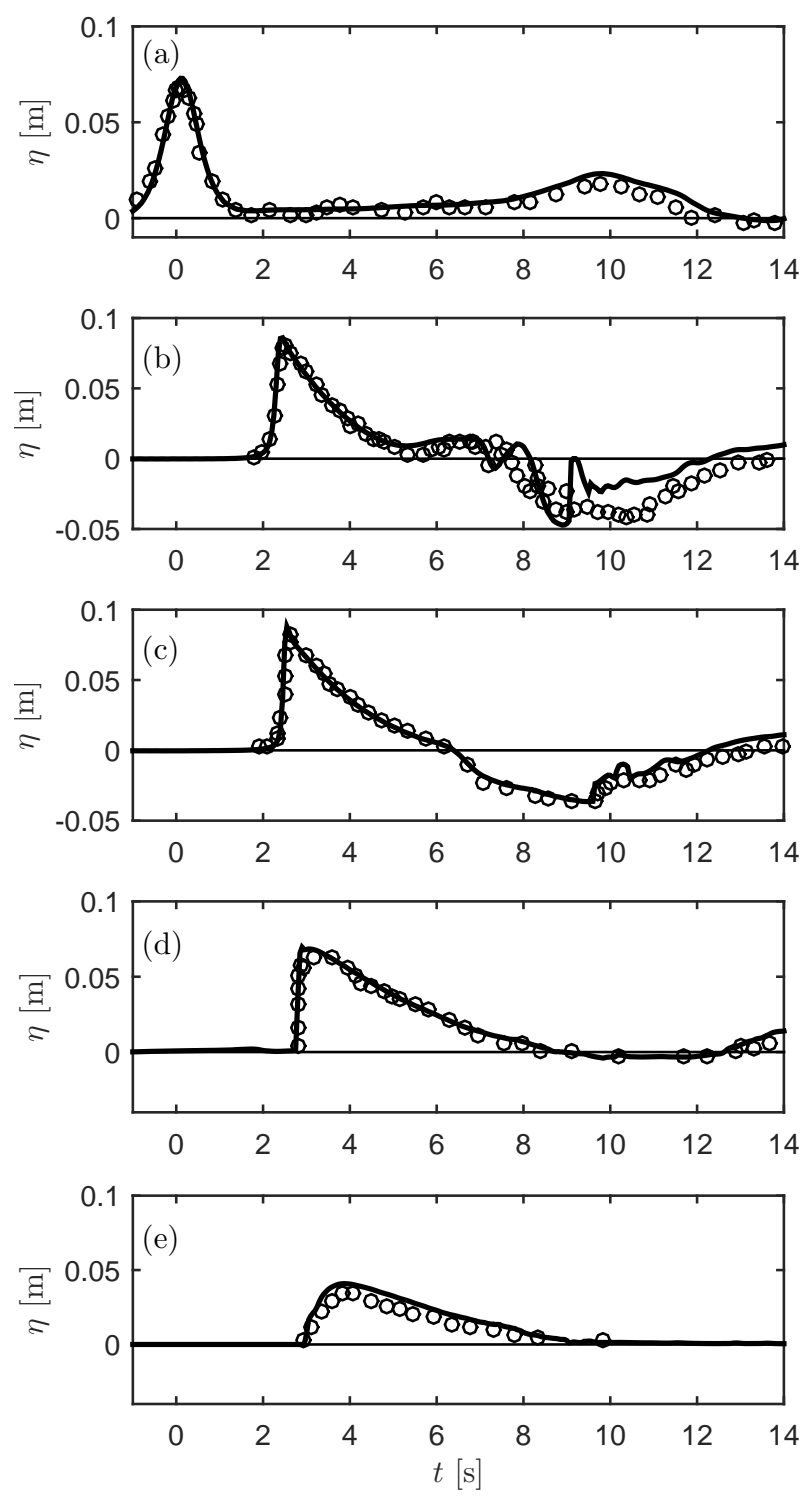

Figure 5: Comparison between modelled (-) and experimental (o) from Sumer et al. (2011) surface elevations at (a) section 0 , (b) section 1 , (c) section 3 , (d) section 5) and (e) section 8 .

The run-up height in the experiments was estimated as $18 \mathrm{~cm}$ whereas in the simulation it was $21 \mathrm{~cm}$, and is thus slightly overestimated. This is perhaps a bit surprising taking into account the good surface elevation comparison in the swash-zone (Figure 5e). The explanation for this is prob- 
ably due to the near bed cells having somewhat large aspect ratios. In a VOF model, if $\gamma$ is larger than zero, there will be a flux over the cell faces, irrespective of the actual location of the water within the cell. Large aspect ratios may therefore cause the tip of the wave to "smear out." Additionally, spurious velocities in the air phase may have added to the overestimation. The presence of the spurious velocities can be explained by the large density ratio between air and water, meaning that just a small erroneous transfer of momentum across the interface from the heavy to the light fluid will cause a large acceleration of the light fluid. Such spurious velocities have been documented in many places see e.g. Deshpande et al. (2012) and Wemmenhove et al. (2015). In Larsen et al. (2018b), it was shown that these only affect the wave very near the interface, but at the tip of the swash tongue, there are only one or two cells containing water, suggesting that it might have an effect here. In relation to tsunamis, this effect can be considered small, however, as the tsunamis are much longer, and the tip of swash tongue (with only a few cells of water) will only represent a very small fraction of the full tsunami wave.

The comparison between the bed shear stresses at five different cross shore positions is additionally shown in Figure 6 . It can be seen that at all five measurement positions the bed shear stress during run-up is well captured (the first peak). It is slightly underestimated in section 8 (Figure $6 e$ ). Here, however, it is expected that the flow consist of a mixture of air and water, and it is therefore questionable exactly what shear stress was measured by the hot film in the experiments, which was calibrated for pure water. Furthermore, the model in this position also contained a mixture of air and water. For the comparison in Figure 6 (full line) a constant density of $\rho=1000 \mathrm{~kg} / \mathrm{m}^{3}$, was used, but using the actual density of the near bed cell (shown as the dotted line), the non-dimensional shear stress would have been slightly higher than was measured.

During the draw-down larger differences are seen. In sections 1 and 2 (Figure 6a,b) the negative bed shear stress occurs slightly later in the model than in the experiments. These sections are, however, placed right around the position where the hydraulic jump forms (see Figure 3). Here slight differences between modelled and experimental surface elevations were seen (Figure 5b). The poorer comparison at this position is therefore apparently more due to the inability of the model to capture details within the hydraulic jump. At sections 5 and 6 the bed shear stress of the draw-down is also well captured by the model (Figure 6c,d). Finally in section 8 the bed shear stress during the draw-down is underestimated (Figure 6e). We ascribe this underestimation to the presence of spurious velocities in the air, which are in 

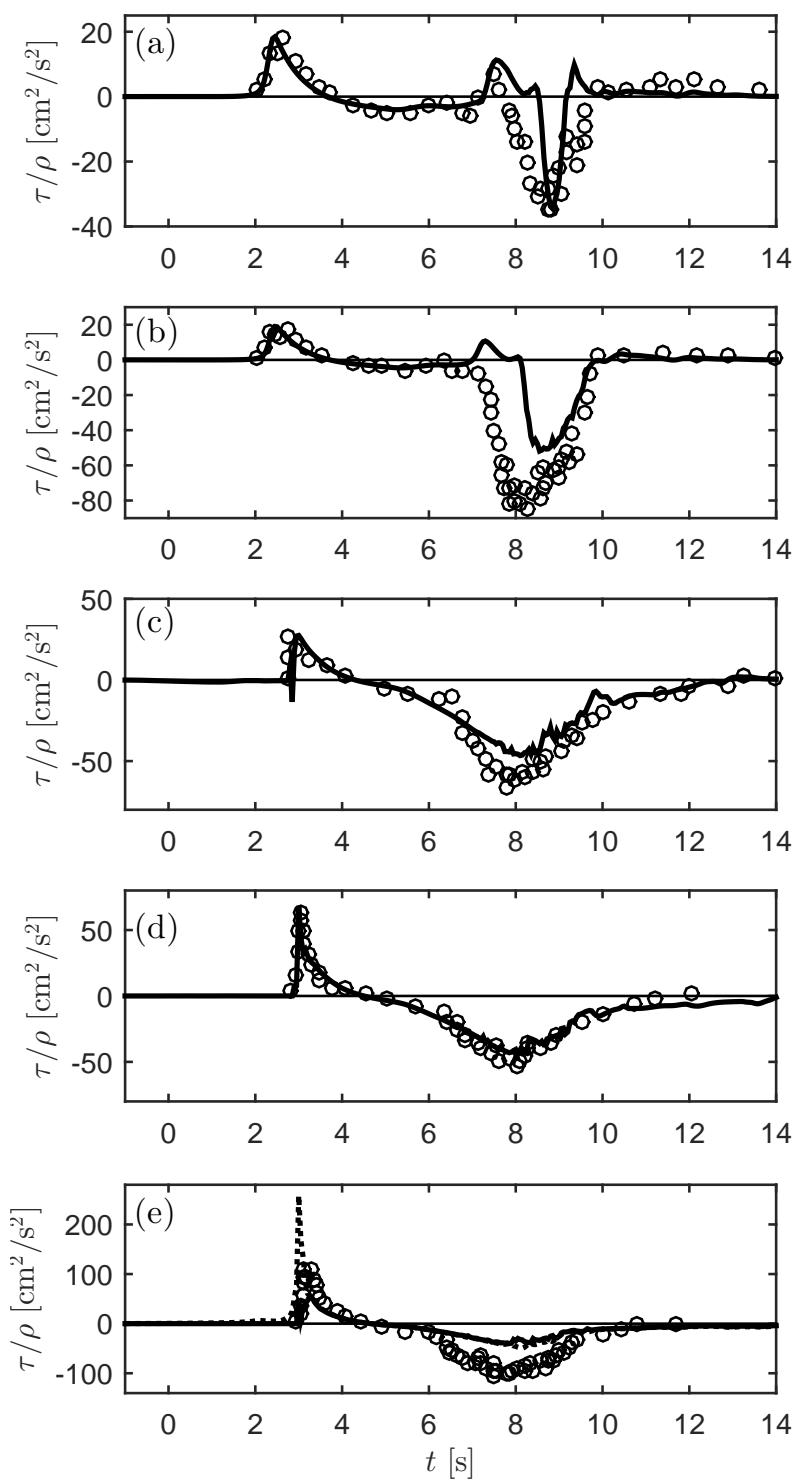

Figure 6: Comparison between modelled using $\rho=1000 \mathrm{~kg} / \mathrm{m}^{3}(-)$, using $\rho_{\text {cell }}(:)$ and experimental (o) from Sumer et al. (2011) bed shear stresses at (a) section 1, (b) section 2 , (c) section 5, (d) section 6 and (e) section 8. The dotted line in (e) is calculated using the actual density of the near-bed cell.

the opposite direction of the flow. In general the comparison of the bed shear stress is acceptable. There is some uncertainty regarding the performance right around the air/water/bed interface, but in relation to tsunamis this 
uncertainty can be considered small, as a given cross shore position will either be fully in air or in water for the vast majority of a tsunami event.

\section{Case selection and model setup}

In this study we will now consider the simple canonical case of $2 \mathrm{D}$ tsunami waves propagating over an initial constant depth region, before running up a constant slope. As an inspiration for the present study we use the well-known Mercator yacht signal, taken during the Indian Ocean tsunami in 2004, which similarly has inspired other tsunami studies see e.g. Williams and Fuhrman (2016) and Larsen et al. (2017). The leading wave was estimated by Madsen and Fuhrman (2008) to be approximately sinusoidal and to have a wave height of $5 \mathrm{~m}$ and a period of $T=13 \mathrm{~min}$ at a water depth of $h=14 \mathrm{~m}$. This shape, wave height and period is obviously just one realization of a tsunami signal. As an example of the variability of tsunami signals please see Kawai et al. (2013). For the present simulations we will use various generalized $\mathrm{N}$-waves, but all with a crest-to-trough wave height of $H=5 \mathrm{~m}$ and a period of $T=13 \mathrm{~min}$ at a water depth of $h=14$ $\mathrm{m}$, similar to the measurements from the Mercator yacht.

Unless stated otherwise the waves will be initialized on a flat bed, which is one wave length long, such that the flat part of the domain houses the entire wave. The waves will then propagate and deform before reaching a constant slope region, where the slope will be systematically varied. A general setup of the computational domain can be seen in Figure 7. Note that $x=0$ now defines the initial shoreline.

A zero gradient boundary condition was applied on the seaward boundary allowing water to flow out and thereby we do expect the seaward boundary to have any effect on the findings presented.

It is important to stress that the wave reaching the slope will no longer be precisely given by equation (23), as the wave, similar to the validation case in Figure 2, deforms while propagating. Furthermore, as will be shown later, the presence of the toe also effects surface elevation time series at the toe of the slope such that the surface elevations at the toe will be slightly different for differing slopes, even with the same initial wave form.

Table 1 gives a summary of the considered cases. In the first half of the table $A_{2}=0$ and therefore these waves are single waves, with only a positive displacement. The second half of the table contains $\mathrm{N}$-waves with a leading depression. The periods and phase shifts of the $\mathrm{N}$-waves are chosen to yield the same wave length and crest-to-trough wave height as the single 


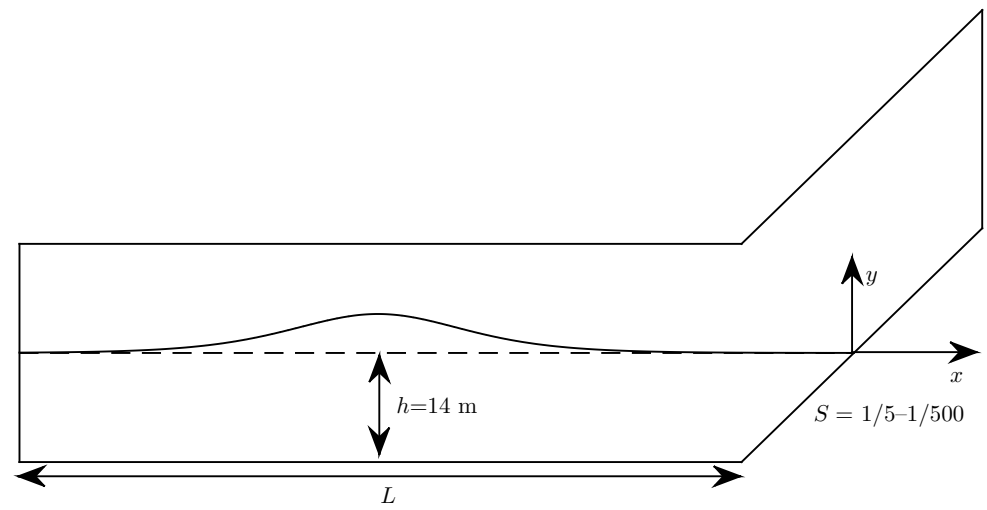

Figure 7: Layout of the computational domain, with origo positioned at the original shoreline.

wave cases. Only a leading depression wave was chosen, and not a leading elevation $\mathrm{N}$-wave, as this would run-up similar to the single wave.

$A_{0}$ is the wave amplitude at the toe of the slope and $\xi$ is the surf similarity parameter, which, as described by Madsen and Fuhrman (2008) and Madsen and Schäffer (2010) can be expressed as

$$
\xi \equiv \frac{S}{\sqrt{H_{0} / L_{\infty}}}=\sqrt{\pi}\left(\frac{A_{0}}{h_{0}}\right)^{-1 / 2}\left(\frac{\Omega^{2} h_{0}}{g S^{2}}\right)^{-1 / 2},
$$

where $H_{0}$ is the wave height at the toe, $h_{0}=14 \mathrm{~m}$ is the depth at the toe, $L_{\infty}=g T^{2} /(2 \pi)$ and $\Omega=2 \pi / T$ is the effective angular frequency. Also included in the table is the modelled run-up height $R_{u p}^{*}$ as well as the maximum inundation speed $V_{i n}^{*}$. Here $V_{i n}$ is calculated as

$$
V_{\text {in }}=\frac{\partial x_{\text {shore }}}{\partial t},
$$

where $x_{\text {shore }}$ is the horizontal position of the shoreline taken as the most landward position where $\gamma>0.5$ at a distance $2 \mathrm{~cm}$ above the bed. At first the threshold was used on the bottom cells, but this resulted in the shoreline barely retreating during draw-down as a very thin layer of water remained for a long time. During run-up the two approaches yielded very similar results . $V_{i n}^{*}$ is subsequently found as the maximum inundation speed averaged over a minute. This particular time for averaging was chosen as we later discuss the chance of outrunning the tsunamis, and a minute seem 
Table 1: Labels, slopes, initial wave parameters and computed run-up heights and inundation speeds of the simulated cases. The cases in bold represent the cases to be discussed in detail in the following sections.

\begin{tabular}{ccccccccccccc}
\hline Name & $\mathrm{S}$ & $A_{1}[\mathrm{~m}]$ & $A_{2}[\mathrm{~m}]$ & $T_{1}[\mathrm{~s}]$ & $T_{2}[\mathrm{~s}]$ & $t_{1}[\mathrm{~s}]$ & $t_{2}[\mathrm{~s}]$ & $x_{0}[\mathrm{~m}]$ & $A_{0}[\mathrm{~m}]$ & $\xi$ & $R_{u p}^{*}[\mathrm{~m}]$ & $V_{i n}^{*}[\mathrm{~m} / \mathrm{s}]$ \\
\hline S005 & $\mathbf{1 / 5}$ & $\mathbf{5}$ & $\mathbf{0}$ & $\mathbf{7 8 0}$ & $\mathbf{0}$ & $\mathbf{0}$ & $\mathbf{0}$ & $\mathbf{- 4 6 4 0 . 5}$ & $\mathbf{1 0 . 8}$ & $\mathbf{4 1 . 9}$ & $\mathbf{1 1 . 3}$ & $\mathbf{0 . 8 1}$ \\
S015 & $1 / 15$ & 5 & 0 & 780 & 0 & 0 & 0 & -4780.5 & 10.1 & 14.4 & 14.5 & 3.01 \\
S030 & $1 / 30$ & 5 & 0 & 780 & 0 & 0 & 0 & -4990.5 & 8.03 & 8.11 & 16.3 & 6.13 \\
S075 & $1 / 75$ & 5 & 0 & 780 & 0 & 0 & 0 & -5620.5 & 5.49 & 3.92 & 15.4 & 11.4 \\
S100 & $\mathbf{1} / \mathbf{1 0 0}$ & $\mathbf{5}$ & $\mathbf{0}$ & $\mathbf{7 8 0}$ & $\mathbf{0}$ & $\mathbf{0}$ & $\mathbf{0}$ & $\mathbf{- 5 9 7 0 . 5}$ & $\mathbf{5 . 3 4}$ & $\mathbf{2 . 9 8}$ & $\mathbf{1 4 . 4}$ & $\mathbf{1 3 . 2}$ \\
S200 & $1 / 200$ & 5 & 0 & 780 & 0 & 0 & 0 & -7370.5 & 5.13 & 1.52 & 11.0 & 14.4 \\
S500 & $\mathbf{1 / 5 0 0}$ & $\mathbf{5}$ & $\mathbf{0}$ & $\mathbf{7 8 0}$ & $\mathbf{0}$ & $\mathbf{0}$ & $\mathbf{0}$ & $\mathbf{- 1 1 5 7 1}$ & $\mathbf{5 . 0 2}$ & $\mathbf{0 . 6 2}$ & $\mathbf{6 . 1 8}$ & $\mathbf{1 3 . 8}$ \\
S030L & $\mathbf{1} / \mathbf{3 0}$ & $\mathbf{5}$ & $\mathbf{0}$ & $\mathbf{7 8 0}$ & $\mathbf{0}$ & $\mathbf{0}$ & $\mathbf{0}$ & $\mathbf{- 9 5 6 1}$ & $\mathbf{8 . 5 6}$ & $\mathbf{7 . 8 6}$ & $\mathbf{1 6 . 8}$ & $\mathbf{8 . 3 3}$ \\
\hline N005 & $1 / 5$ & 2.52 & 2.52 & 520 & 520 & 130 & -130 & -4640.5 & 5.07 & 61.2 & 8.75 \\
N015 & $1 / 15$ & 2.52 & 2.52 & 520 & 520 & 130 & -130 & -4780.5 & 4.73 & 21.1 & 11.6 & 4.13 \\
N030 & $1 / 30$ & 2.52 & 2.52 & 520 & 520 & 130 & -130 & -4990.5 & 4.18 & 11.2 & 12.0 & 8.26 \\
N075 & $1 / 75$ & 2.52 & 2.52 & 520 & 520 & 130 & -130 & -5620.5 & 2.66 & 5.63 & 11.3 & 11.4 \\
N100 & $\mathbf{1 / 1 0 0}$ & $\mathbf{2 . 5 2}$ & $\mathbf{2 . 5 2}$ & $\mathbf{5 2 0}$ & $\mathbf{5 2 0}$ & $\mathbf{1 3 0}$ & $\mathbf{- 1 3 0}$ & $\mathbf{- 5 9 7 0 . 5}$ & $\mathbf{2 . 4 1}$ & $\mathbf{4 . 4 3}$ & $\mathbf{9 . 6 4}$ & $\mathbf{1 1 . 1}$ \\
N200 & $1 / 200$ & 2.52 & 2.52 & 520 & 520 & 130 & -130 & -7370.5 & 2.51 & 2.17 & 4.89 & 10.3 \\
\hline
\end{tabular}

appropriate in this regard. Using the entire time until maximum inundation did not properly represent how the tsunamis would be experienced, as the initial inundation in some cases were slow followed by a significantly more rapid inundation speed. Similarly, averaging over a significantly shorter time did not seem representative of the scenarios as local inundation speeds could be very high when only using a few seconds.

Figure 8 shows a time signal of the initial single wave and $\mathrm{N}$-wave used in the simulations. Here it can clearly be seen that the two initial signals represent quite different tsunami realizations despite having the same crestto-trough height and period. The roughness for the present cases is given by $k_{s}=2.5 d$ with $d=4 \cdot 10^{-4} \mathrm{~m}$. For all cases the domain is discretized into cells $\Delta y=0.25 \mathrm{~m}$ and $\Delta x=0.5 \mathrm{~m}$ and from $5 \mathrm{~m}$ above the bed and lower the grid is gradually refined (using 51 cell) in the vertical with near-bed cells having $\Delta y=0.0014 \mathrm{~m}$ corresponding to $\delta y / k_{s}=1.4$. The bottom $0.5 \mathrm{~m}$ is discretized into 21 cells. The simulations to be presented in what follows each took between two weeks and two months to complete when simulated in parallel on 12 modern processors (Intel Xeon Processor E5-2680 v2).

\section{Model results: Run-up heights and inundation speeds}

This section will describe and discuss the modelled run-up heights and inundation speeds. Before continuing, the effect of the slope on the surface 


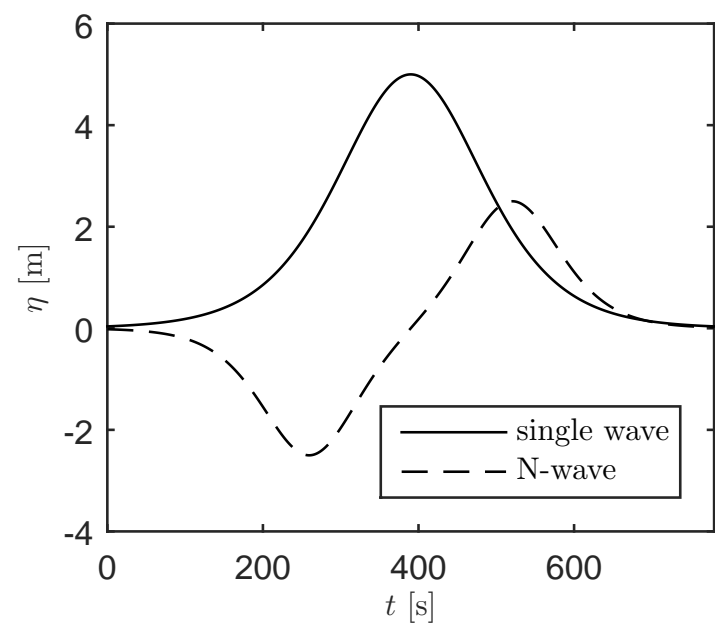

Figure 8: Time signal of the initial waves.

elevation signal at the toe of the slope will be discussed, as this affects the analysis of the run-up.

As previously stated, the slope itself actually has an impact on the surface elevation at the toe of the slope, such that tsunamis with identical initial wave fields, running up different slopes, will have different surface elevation signals at the toe of the slope. To illustrate this Figure 9 shows the surface elevations as a function of time for both single waves and $\mathrm{N}$-waves for three different slopes. Most noticeably both cases with $S=1 / 5$ result in much larger wave heights than the initial wave signal (see Figure 8) and are substantially higher than the other cases. This can be explained by the tsunami being reflected even before the crest of the tsunami arrives at the slope. The reflected part of the tsunami is then super-positioned on top of the incoming wave, resulting in higher surface elevations. This is essentially a transient standing wave, similar to the periodic form shown in Madsen and Fuhrman (2008). For the cases with $S=1 / 30$ the peak of the surface elevations comes at a later time. This is again due to reflection and the reflected wave interacting with the incoming wave. For the single wave with $S=1 / 100$, the surface elevation signal shows two distinct peaks, one for the incoming and one for the reflected wave. However, following the crest of the incoming wave, the surface elevation never returns to the still water level before the arrival of the reflected wave. For the single wave, this only occurs for the very mild slope of $S=1 / 500$ (not included in the figure). For the N-waves, the slope of $S=1 / 100$ is mild enough that the reflected and the 
incoming wave can be clearly distinguished.
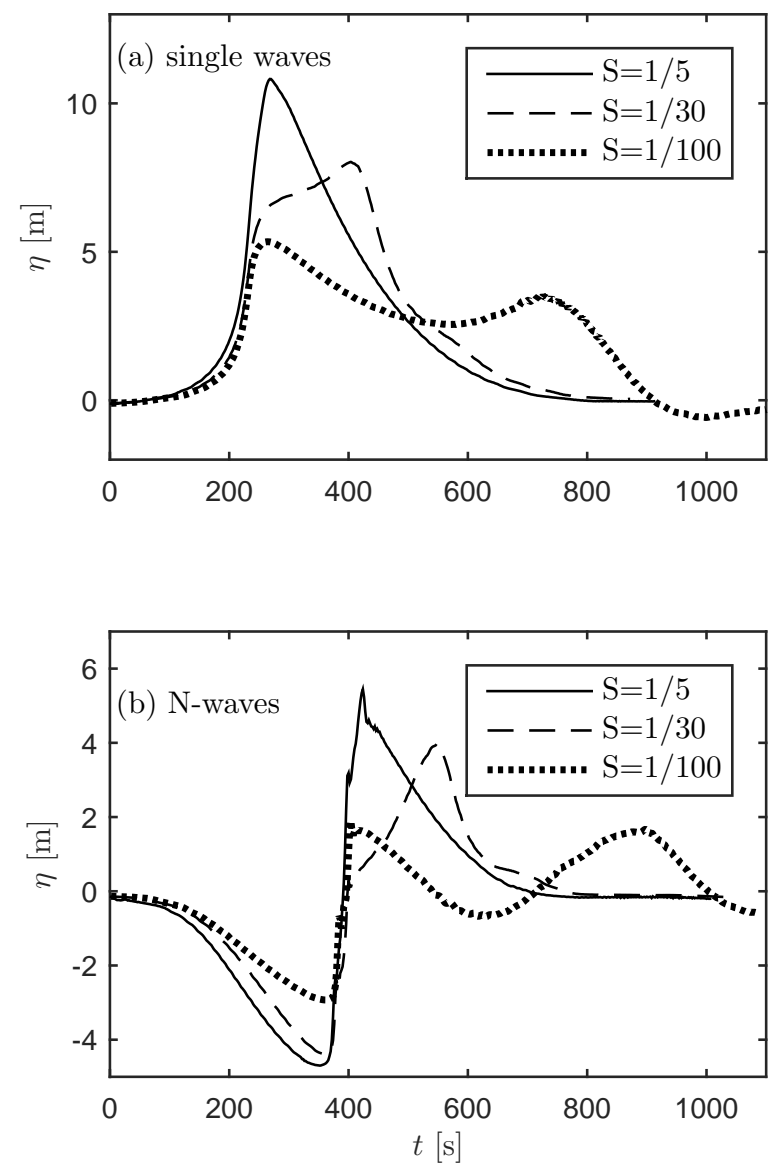

Figure 9: Development of the surface elevation at the toe of the slope for (a) single waves and (b) N-waves.

The surface elevations presented here demonstrate the difficulty in identifying incoming and reflected tsunami waves from a surface elevation signal alone. This can pose a challenge when trying to reproduce a tsunami event, using a measured surface elevation signal as an inlet condition in model simulations.

In Madsen and Schäffer (2010) expressions for the run-up height and inundation speed were given as a function of the surf-similarity parameter $\xi$ for both single waves and $\mathrm{N}$-waves propagating on a constant depth be- 
Table 2: Values for $\chi_{\text {elev }}$ and $\chi_{\text {break }}$ for single waves and N-waves, based on the analysis Madsen and Schäffer (2010).

\begin{tabular}{cccc}
\hline Wave type & $\chi_{\text {elev }}$ & $\chi_{\text {break }}$ & $\chi_{\text {velo }}$ \\
\hline single wave & 3.043 & 0.1561 & 2.516 \\
N-wave & 4.397 & 0.0373 & 8.450 \\
Sinusoidal wave & $2 \sqrt{\pi} \approx 3.545$ & $(2 \sqrt{\pi})^{-1} \approx 0.282$ & $2 \sqrt{\pi} \approx 3.545$ \\
\hline
\end{tabular}

fore running up a constant slope, very similar to this study. Their analysis assumes a linear wave at the toe of the slope and although this is not entirely the case in the present study, we will nevertheless compare the run-up heights and inundation speeds from the simulations to the analytical results from Madsen and Schäffer (2010). Their analysis builds on the hodograph transform by Carrier and Greenspan (1958). They then expressed their solution in terms of both inverse Fourier transformations and convolution integrals to arrive at a solution for the time varying run-up. They provided a breaking criterion which corresponds to the theory breaking down, which happens when the Jacobian vanishes. This corresponds to the time and position where the wave front becomes vertical.

By this analysis the maximum run-up is then given by

$$
R_{u p}^{*}=\min \left(R_{u p}, R_{u p}^{\text {limit }}\right)
$$

477 where

$$
\frac{R_{u p}}{A_{0}}=\chi_{e l e v} \pi^{1 / 4}\left(\frac{A_{0}}{h_{0}}\right)^{-1 / 4} \xi^{-1 / 2},
$$

478 is the expression for tsunamis not expected to break, and

$$
\frac{R_{u p}^{\text {limit }}}{A_{0}}=\frac{\chi_{\text {elev }} \chi_{b r e a k}}{\pi} \xi^{2}
$$

479 is the expression for tsunamis where breaking could be expected to occur. 480 Similarly the maximum inundation speed can be found as

$$
V_{i n}^{*}=\min \left(V_{i n}, V_{i n}^{l i m i t}\right)
$$

481 where

$$
\frac{V_{i n}}{\sqrt{g A_{0}}}=\chi_{v e l o} \pi^{3 / 4}\left(\frac{A_{0}}{h_{0}}\right) \xi^{-3 / 2}
$$


and

$$
\frac{V_{\text {in }}^{\text {limit }}}{\sqrt{g A_{0}}}=\frac{\chi_{\text {velo }} \chi_{\text {break }}}{\sqrt{\pi}} \xi
$$

In the above $\chi_{\text {elev }}, \chi_{\text {break }}$ and $\chi_{\text {velo }}$ comes from the analytical analysis of Madsen and Schäffer (2010). They are different for sinusoidal, single- and $\mathrm{N}$-waves and the values used are presented in Table 2 . Note that the values in Table 2 for both sinusoidal and single waves are identical to those presented in the text in Madsen and Schäffer (2010), but that the values for N-waves are different. These have been re-calculated following the approach described in Madsen and Schäffer (2010), as the N-waves in the present study use a different phase shift and did not have $\Omega=\Omega_{1}=\Omega_{2}$ as simply assumed in Madsen and Schäffer (2010).

Figure 10 compares the simulated run-up heights with those obtained with equation (27), for the single waves (included in the figure are also selected labels for those cases described in detail in the next section). As previously shown the amplitudes of the incoming waves are not identical with the different slopes. Therefore the analytical curve has been created using the initial wave amplitude $A_{0}=5 \mathrm{~m}$, whereas the simulated results are based on the actual $A_{0}$ at the toe (indicated in Table 1). This is the most legitimate comparison possible since the Madsen and Schäffer (2010) incident wave contained both the incoming and reflected wave. The analytical solutions of Madsen and Schäffer (2010) are actually a family of curves, and for the cases with $A_{0}$ higher than $5 \mathrm{~m}$, the analytical curve would be positioned slightly, but not significantly, lower than that shown in Figure 10.

The analytical curve has two distinct regions. Starting from small $\xi$ and increasing the expected run-up heights increase rapidly with $\xi$. This part of the curve (full line) represents the line given by (29), which is the breakdown limit of the theory. To the right of the peak, the curve follows a line given by (28) which corresponds to no breaking and hence full reflection at the shore. Included in the figure is also a linear function given by

$$
\frac{R_{u p}^{\text {Hunt }}}{A_{0}}=\xi
$$

which was suggested by Hunt (1959) to be a better estimate for breaking waves, see also Madsen and Fuhrman (2008) who used this for irregular waves. An alternative formulation for the run-up is therefore

$$
R_{u p}^{*}=\min \left(R_{u p}, R_{u p}^{\text {Hunt }}\right)
$$


which is depicted as a dashed line (This was also used by Madsen and Fuhrman (2008)).

It can be seen that, even though the assumption of linearity at the toe is violated the analytical solution and the simulated results agree reasonably well in the region where (28) is dominating. Similar to observations by Park et al. (2015), the run-up heights are underestimated with the analytical expressions in the region where (29) is dominating. Here the expression of Hunt (1959) seems to give more accurate predictions. This can be explained by the breakdown of NLSW theory not directly corresponding to breaking. Furthermore, even after NLSW theory predicts a vertical surface elevation (approximately interpreted as the tsunamis breaking), the tsunami waves continue to run-up.

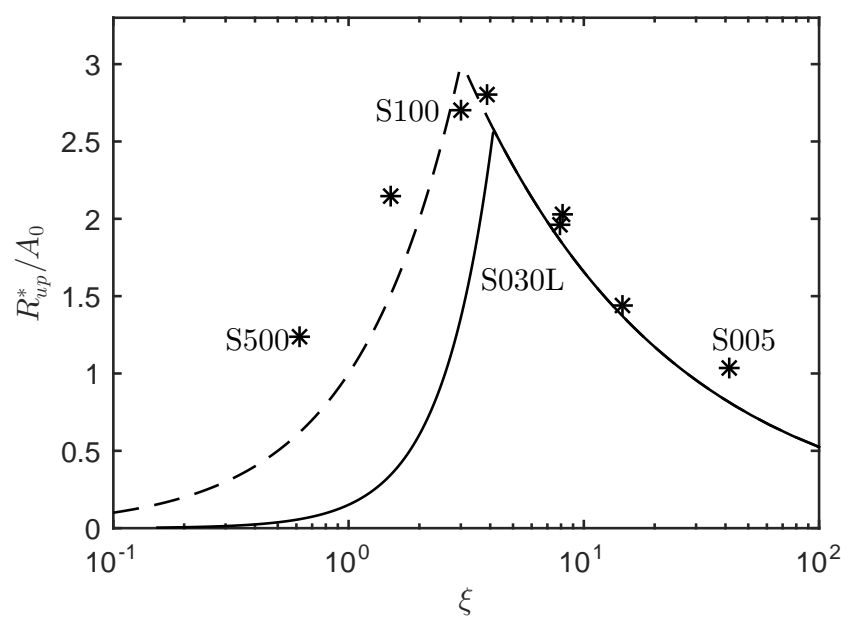

Figure 10: Comparison between modelled (*), analytical (27)(-) and (34)(- -) run-up of the single wave as a function of surf-similarity parameter.

525 Figure 11 compares the simulated run-up heights with those obtained utilizing equation (27) for the N-waves. Similar to before the analytical curve is made using the initial wave amplitude $A_{0}=2.5 \mathrm{~m}$ and the modelled results have used the actual $A_{0}$ at the toe. 


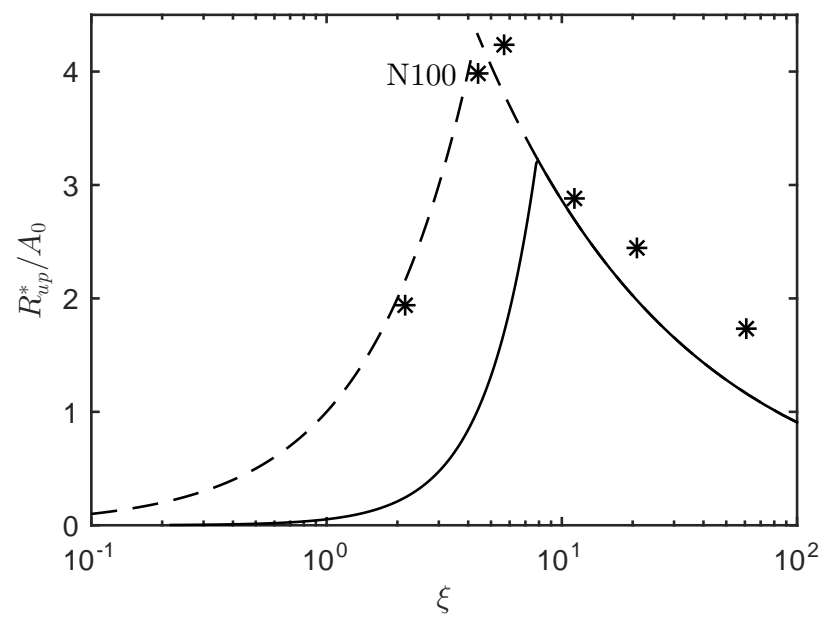

Figure 11: Comparison between modelled (*), analytical (27) (-) and (34) (- -) run-up of the N-wave as a function of surf-similarity parameter.

where $V_{\text {in }}^{\text {Break }}$ has been approximated by

$$
V_{\text {in }}^{\text {Hunt }}=\frac{\Omega R_{u p}^{\text {Hunt }}}{S}
$$

Here, in general, a good agreement between the modelled run-up heights and the analytical run-up heights is again achieved. Similar to before, the modelled run-up heights are slightly above those obtained with the analytical approach in the region dominated by (29) and the expression of Hunt (1959) (33), depicted as a dashed line seems more appropriate.

Figure 12 compares the simulated maximum inundation speed with the that obtained using equation (30). Included as dashed line is also an alternative expression given by

$$
V_{i n}^{*}=\min \left(V_{i n}, V_{i n}^{\text {Break }}\right)
$$

The above formulation is a way to estimate the inundation speed based on the predicted run-up height in situations where breaking would be expected to occur and follows the relation between run-up height slope and frequency for sinusoidal waves (see Madsen and Fuhrman (2008)). Similar to the predicted run-up height it can be seen that the analytical expression by Madsen and Schäffer (2010) gives a reasonable approximation for the inundation speed in cases where waves are not predicted to break (right part of the solid 


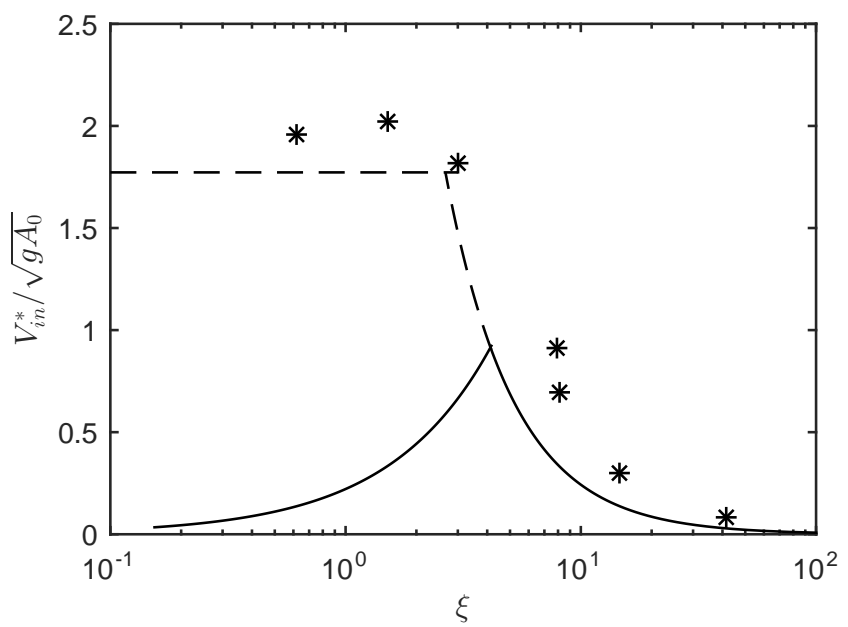

Figure 12: Comparison between modelled (*), analytical (30) (-) and (35) (- -) maximum inundation speed for the single wave as a function of surf-similarity parameter.

line). In cases where waves are predicted to break the prediction based on the run-up height from Hunt (1959), (36) shown as a dashed line seem to more appropriate, and as whole the combined expression in (35) seems to give a reasonable approximation, although this expression in general slightly underestimates the inundation speed compared to the model.

Finally, Figure 13 compares the simulated maximum inundation speed with that obtained using (30) and (35). Similar to the results for the single waves, the combined expression (35) gives a reasonable prediction, although it also slightly underestimates the inundation speed compared to the model.

Overall, based on the decent match with the more advanced CFD simulations, we would argue that the combined expressions from Madsen and Schäffer (2010) and Hunt (1959), expressed in (34) and (35), performs relatively well in predicting the run-up heights and inundation speeds across a wide range of cases, and can hence be used as a quite reasonable first assessment of the run-up height and inundation speed, respectively. As they are based on NLSW equations, however, the detailed information of the actual process is limited. This information can, in contrast, be gathered by the advanced CFD model, as will be done in the following sections. 


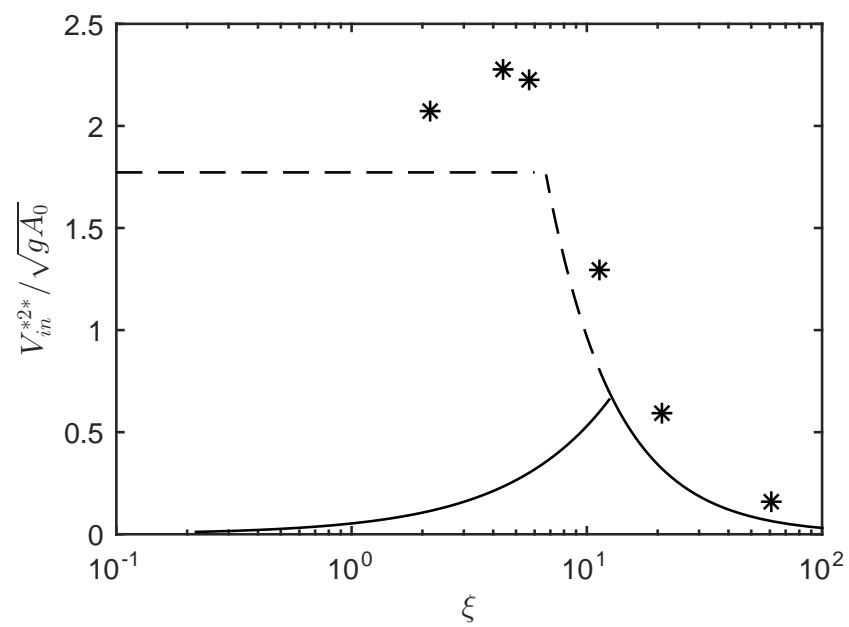

Figure 13: Comparison between modelled (*), analytical (30) (-) and (35) (- -) maximum inundation speed for the $\mathrm{N}$-wave as a function of surf-similarity parameter.

\section{Qualitative run-up description}

The various tsunami signal and slope combinations can yield a wide array of different run-up types. According to Sriram et al. (2016), Shuto (1985) states that the observed tsunamis hitting the coast can broadly be placed into three categories; (1) rapidly rising tide, (2) breaking bore or "wall of water" and (3) undular bore. These three run-up types have all been experienced in the present simulations although we will recategorize these as:

1) Surging tsunami

2) Breaking bore

3) Undular bore

This change is done as we do not approve of the phrase "tide" when describing a tsunami and second that we do like the phrase "wall of water" as this is more of a popular description. We would also like to add that some cases appeared initially as undular bores but turned into breaking bores before hitting the coast, and this we will define as a fourth (intermediate) category:

4) Undular bore evolving into a breaking bore

In what follows, based on the highly resolved CFD results, we will now describe and study in detail the characteristics of the run-up process for each of these categories. Additionally, we will discuss different run-up features 
Table 3: Sections, run-up types, case names and computed maximum inundation speed of the cases used for the detailed discussion.

\begin{tabular}{cccc}
\hline Section & Run-up type & Case & $V_{i n}^{*}[\mathrm{~m} / \mathrm{s}]$ \\
\hline 6.1 & Surging tsunami & $\mathrm{S} 005$ & 0.81 \\
6.2 & Breaking-bore & $\mathrm{S} 100$ & 13.2 \\
6.3 & Undular bore turning into a breaking bore & $\mathrm{S} 500$ & 13.8 \\
6.4 & Undular bore & $\mathrm{S} 030 \mathrm{~L}$ & 8.33 \\
6.5 & Breaking bore & $\mathrm{N} 100$ & 11.1 \\
\hline
\end{tabular}

between single- and N-waves. The cases chosen to illustrate these different run-up categories are listed in Table 3.

\subsection{Surging tsunami}

We will first consider the surging tsunami run-up type. As a representative of this type we choose case S005, which is a single wave running up a steep $1 / 5$ slope (see again Table 1 for a full description). Figure 14 shows results of surface elevations and velocities from case S005 at several different instants. In Figure 14a the initial wave can be seen. In Figure 14b the wave has steepened slightly and has started to inundate the coast, and in Figure $14 \mathrm{c}$ the wave is at its maximum run-up. Finally, in Figure $14 \mathrm{~d}$ the reflected wave can be seen with a steep wave front which ultimately evolves into an undular bore as shown in Figure 14e. From this representation it is very clear that the steep slope of $1 / 5$ is experienced almost as a vertical wall by the long tsunami, which is fully reflected.

It is noteworthy that there is a phase shift between the maximum velocity and the maximum surface elevation, as can be seen in Figure 14c. This shift can more clearly be seen from a time perspective and therefore Figure 15 a shows a time series of the surface elevations and velocities at $x=0$, corresponding to the original shoreline. In Figure 15b the temporal evolution of the horizontal position of the shoreline is shown. From Figure 15a the phase-shift between the maximum free stream velocity and the maximum surface elevation is completely clear. This phase shift is very similar to what has been observed beneath the 2010 Chilean tsunami at Monterey Bay by Lacy et al. (2012), and is a result the steep slope acting as a vertical wall, essentially creating a standing wave. This explanation, we believe, provides an alternative and more likely (and simpler) explanation for the phase shift, than that given by Lacy et al. (2012). They explained the phase shift through a near-bed momentum balance, where the bed friction, they argued, resulted in the $90^{\circ}$ phase lag between $\eta$ and $u$. The analogy to a 
$u[\mathrm{~m} / \mathrm{s}]$
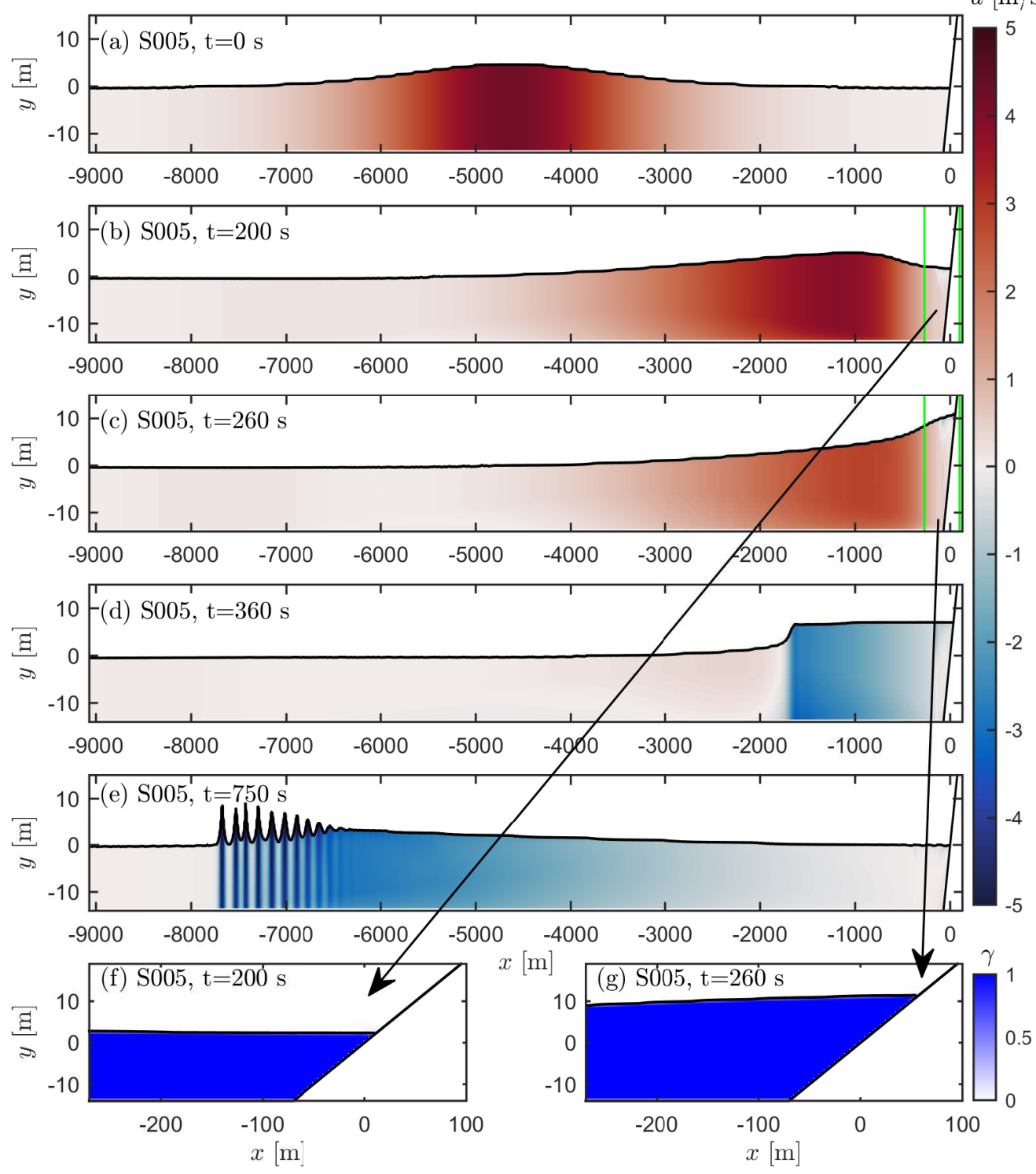

Figure 14: Surface elevation and velocities of S005 at different times. Note that this figure is not to scale.

standing wave explains this observation in a much simpler manner. It is worth noting that this is also reflected in the new edition of the ASCE 7-16 

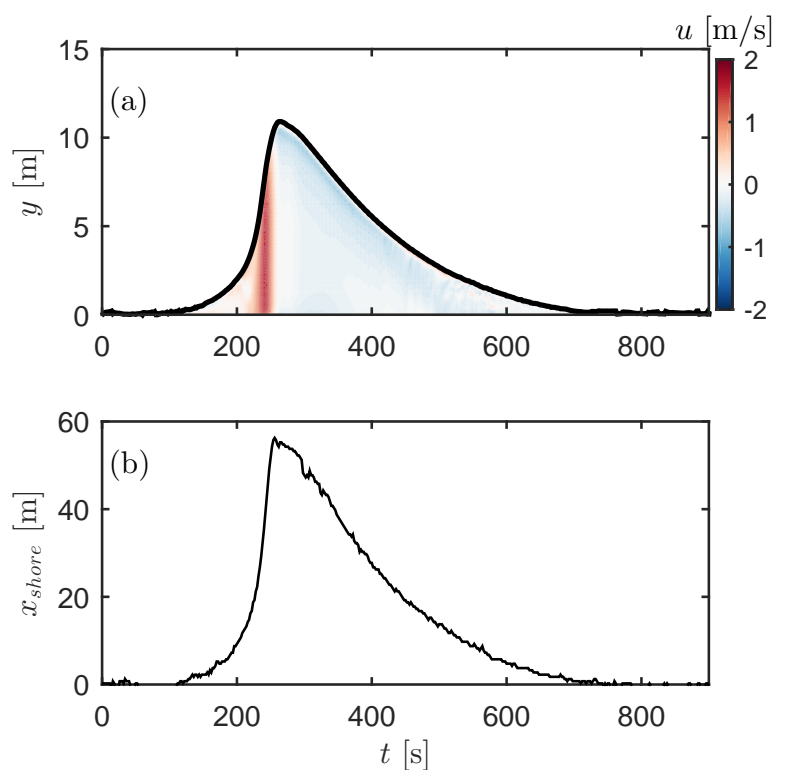

Figure 15: Results for case S005 showing (a) Velocities and surface elevations at $x=0$, (b) the horizontal position of the shoreline.

standard on tsunami loads and effects (ASCE, 2016). Here a tsunami load case 2 is defined, where a flow depth of $2 / 3$ of the maximum flow depth with maximum flow velocity will be used for tsunami design. This is similar to prescribing a phase shift between the maximum surface elevation and maximum velocity.

While inundating the tsunami wave front is almost horizontal as can also be seen in Figure 14f-g, which shows zoomed in positions of the wave fronts. At the same time, the increase in water depth at the original shoreline is not very rapid, as illustrated in Figure 15a. Over the initial approximately $3 \mathrm{~min}=180 \mathrm{~s}$ the depth at the shore goes from $10 \mathrm{~cm}$ to $1 \mathrm{~m}$. From here the increase in water depth is faster and after an additional $1.5 \mathrm{~min}$ (to $t=270$ $\mathrm{s}$ in Figure 15a) the depth increases from approximately $1 \mathrm{~m}$ to $10 \mathrm{~m}$. Although the increase in water depth is large, the duration is still the order of minutes rather than seconds. Finally, Figure 15b illustrates that the inundation speed is indeed very low. The fastest inundation speed (averaging over a minute) is reached during $t=194-254 \mathrm{~s}$, where it reaches approximately $0.8 \mathrm{~m} / \mathrm{s}(2.92 \mathrm{~km} / \mathrm{h}=1.81 \mathrm{mi} / \mathrm{h})$. This present tsunami, could thus easily be outrun. The above observations imply, that the present tsunami will not be seen as a steep wave, but rather "tide-like" as classified by Shuto (1985) 
(it is still obviously important to stress that this is not a tide). A real life example of this run-up type can be found in the youtube video "TD Interesting Topics Tube (2017)" at the time 3:50-5:05 and also at 10:25-12:40. These two sequences show the Tohoku tsunami running into the harbour of Miyako with a seemingly constant, but gradual, increase in water depth. The tsunami enters the harbour next to a seawall, which is finally over-topped in the second video sequence.

As previously mentioned, an undular bore forms at the front of the reflected wave (Figure 14e). This actually also happened in simulated cases S015, S030, N005, N015 and N030. That the undular bore develops in front of the reflected wave is also interesting, and can perhaps help explain why undular bores have been observed at many places in real tsunami events, as reflected tsunami waves will have travelled a long distance in relatively shallow water. The run-up behaviour of undular bores will be discussed later in this section.

\subsection{Breaking bore}

To represent the scenario of tsunamis running up as a breaking bore, we will now show results of case S100, which is a single wave running up a 1/100 slope (see again Table 1). Figure 16 shows surface elevations and velocities from case S100 at different instants. In Figure 16a the initial wave is shown. Figure $16 \mathrm{~b}$ shows the shoaled wave with a steep wave front, and significantly higher velocities, as would be expected. The wave front has actually split at this time, and an undular bore is starting to form, as can be seen in the zoom-in of the wave front in Figure 16e. The short wave riding on top of the main tsunami wave cannot maintain its shape for very long, however, as this wave shoals and steepens. After only four seconds, the shorter wave riding on the front of the tsunami breaks, as seen in Figure 16c, and in more detail in the zoom in of the front in Figure 16f. From here the tsunami runs up the beach like a breaking bore, before it reaches its maximum run-up shown in Figure 16d.

According to the breaking criterion of Madsen and Schäffer (2010) this tsunami would be predicted to break (Figure 10), though it is right near the theoretical threshold. It is important to note, however, that in this case, it was not the main tsunami wave that broke, but rather a short wave riding on the wave front; that the main tsunami front develops into a breaking bore is still generally consistent with this characterization. In all the simulated cases appearing as breaking bores, the wave front initially split into one or more short waves which broke, and then turned the entire wave into a breaking bore. Behind the breaking wave front (Figure 16c,f), the surface 

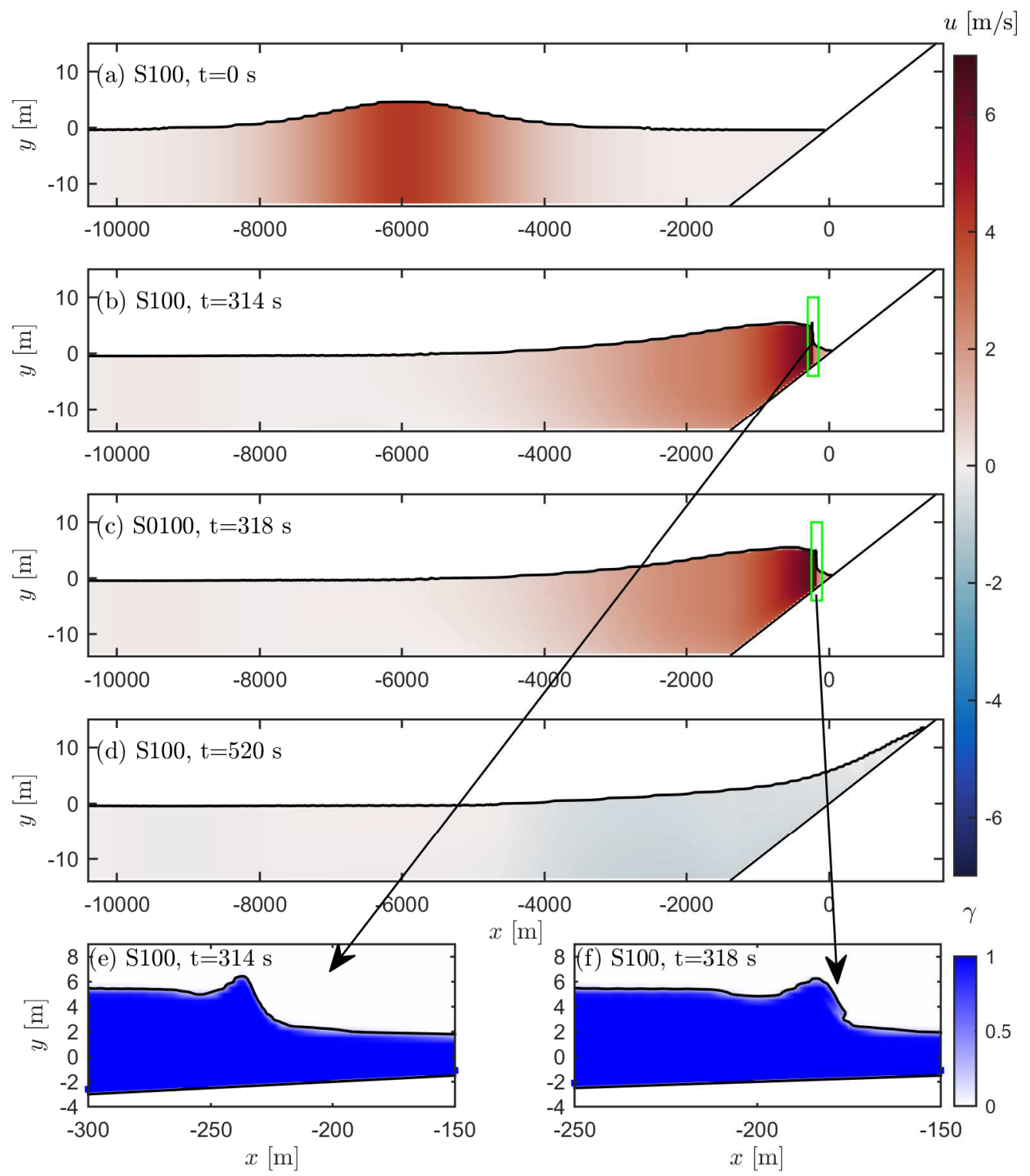

Figure 16: Surface elevation and velocities of S100 at different times. Note that this figure is not to scale.

674 elevations actually continue to increase, indicating that only a very small 675 fraction of the entire wave is affected by breaking. 
In contrast to the previous case (S005) this case did not result in a standing wave, and as a result the free surface elevations and the velocities are in phase. This can be seen more clearly in Figure 17a where the velocities and free-surface elevations at $x=0 \mathrm{~m}$ are shown. In Figure $17 \mathrm{~b}$ the temporal development of the shoreline position is likewise shown. From the representation in Figure 17a it can be seen why the popular term "wall of water" suggested by Shuto (1985) could sometimes be used to describe certain runup scenarios. Similar to before, the depth goes from $10 \mathrm{~cm}$ to $1.3 \mathrm{~m}$ in the first approximately $3 \mathrm{~min}(180 \mathrm{~s})$, but hereafter the depth increases rapidly to $4 \mathrm{~m}$ in a matter of $4 \mathrm{~s}$. Additionally the inundation speed is also much faster, as can be seen from Figure 17b. The fastest inundation speed (averaging over a minute) during $t=344-414 \mathrm{~s}$ corresponds to approximately $13 \mathrm{~m} / \mathrm{s}(47 \mathrm{~km} / \mathrm{h}=29 \mathrm{mi} / \mathrm{h})$. This is in stark contrast to the low inundation speed seen in case S005, and this tsunami could not be outrun. It is worth noting that the shoreline fluctuates a little during draw-down. These fluctuations are caused by small variations in the surface elevation in the very thin layer of water directly just above the bed. These small variations in surface elevations can cause the shoreline to jump as it is determined by the $\gamma$ value of cells $2 \mathrm{~cm}$ above the bed.

Breaking bores have been observed in many instances, and have also often been used as tsunami representations in experiments. Real examples of breaking bores can e.g. be found in videos of the Tohoku tsunami in TD Interesting Topics Tube (2015) at times 3:00-3:15, 4:40-4:48 and 7:508:50. Images of the first situation was also used by Nistor et al. (2017) to justify the choice of wave used in the study. S100 demonstrates the potential devastation that can arise when tsunamis are near the peak of (34) in Figure 10, i.e. where $R_{u p}=R_{u p}^{\text {Hunt }}$ corresponding to

$$
\xi=\chi_{\text {elev }}^{-2 / 3} \pi^{-1 / 6}\left(\frac{A_{0}}{h}\right)^{1 / 6} .
$$

This represents a worst case scenario where the tsunami front steepens significantly, but does not dissipate much energy before reaching the shoreline as the breaking starts very close to the shore or breaking do not occur.

\subsection{Undular bore evolving into a breaking bore}

As could be seen from the previous case, the tsunami started evolving towards an undular bore, but the resulting short waves quickly broke before turning into a full undular bore. There were cases where several shorter waves were riding on the wave front, thus forming a more proper undular 

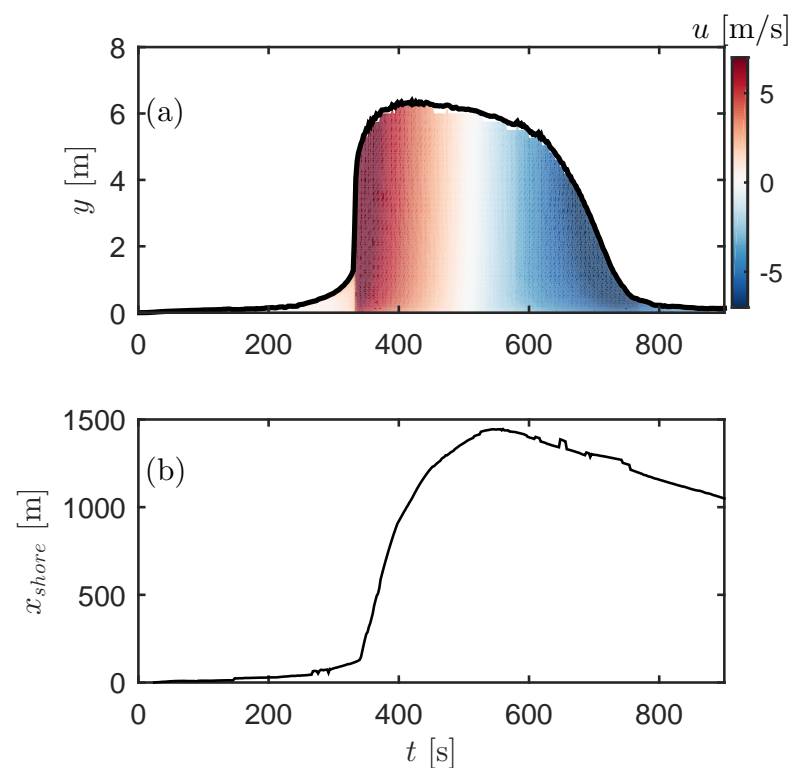

Figure 17: Results for case S100 showing (a) Velocities and surface elevations at $x=0$, (b) the horizontal position of the shoreline.

bore. Similar to before, the individual waves broke before reaching the shore, and as a result turned into a breaking bore. Although these tsunamis essentially run-up as breaking bores, we will illustrate this run-up process in more detail using case S500, which is a single wave running up a 1/500 slope (see again Table 1 as well as Figure 10 for it's position on the run-up curve).

Figure 18 shows results of surface elevations and velocities at different instants from case S500. Figure 18a shows the initial wave. During shoaling an undular bore forms on the tsunami wave front as seen in Figure 18b. Figure 18e shows a zoomed in portion of the wave front, and here the shorter waves riding on the front are clearly visible. These waves, though "short", are still rather large, with wave lengths of approximately $100 \mathrm{~m}$ and wave heights of approximately $10 \mathrm{~m}$, very similar to what have been observed many places, see e.g. Madsen and Fuhrman (2008) or the videos of the Tohoku tsunami in TD Interesting Topics Tube (2015) from at time 2:10$2: 25$.

As the tsunami propagates, the waves riding on the wave front shoal and steepen until they at some point break. This is illustrated in Figure 18c as well as the zoom-in Figure $18 \mathrm{f}$ where the tsunami is seen after propagating 


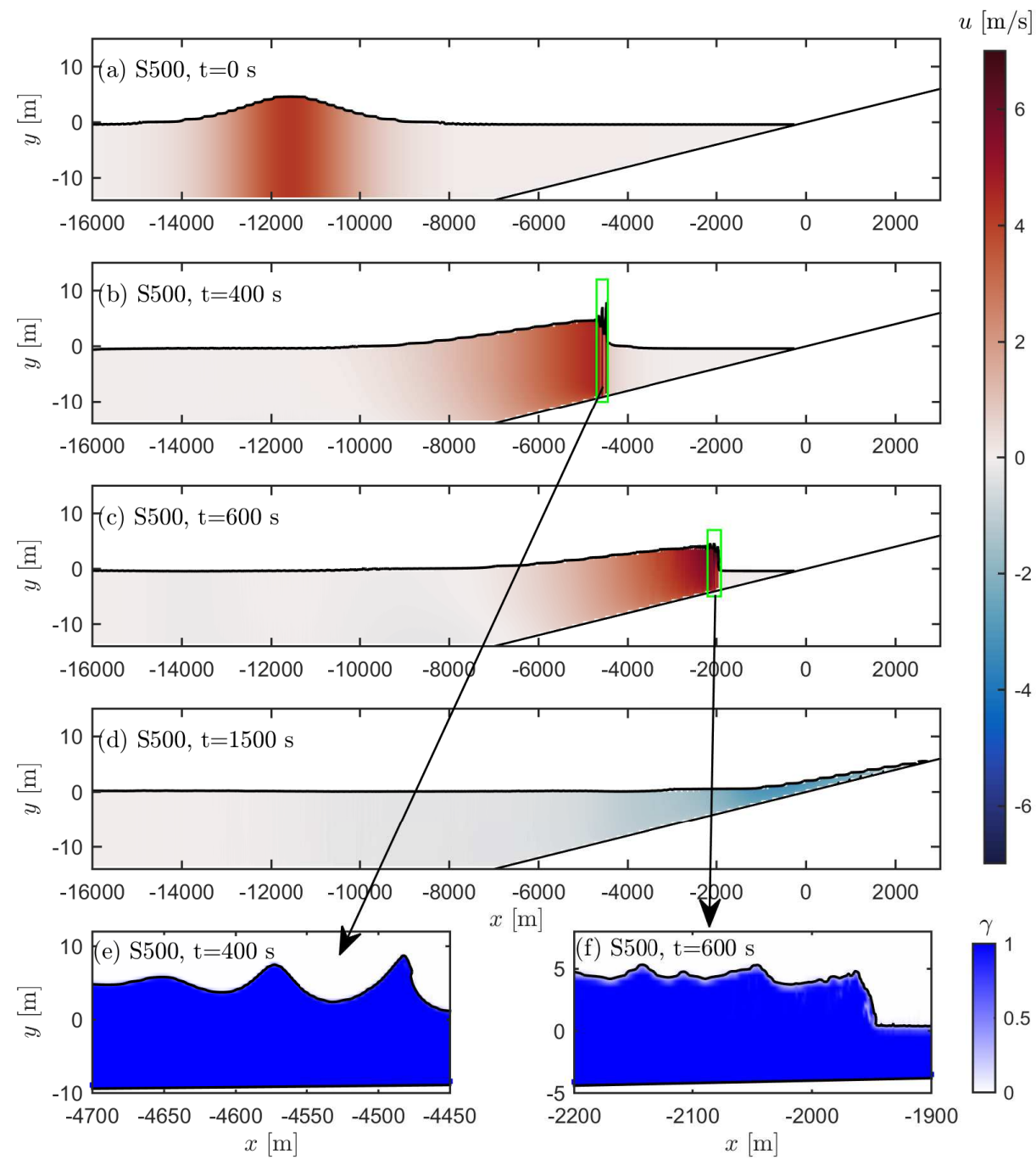

Figure 18: Surface elevation and velocities of S500 at different times. Note that this figure is not to scale.

approximately $2 \mathrm{~km}$ further than in Figure 18b. Figure 18f clearly shows the that the front waves have broken. Traces of the undular bore can still be seen, but when this tsunami finally hits the coast (Figure 18d) there are no undulations at the wave front which is purely a breaking bore. This is also illustrated in Figure 19a where the time series of the surface elevations 

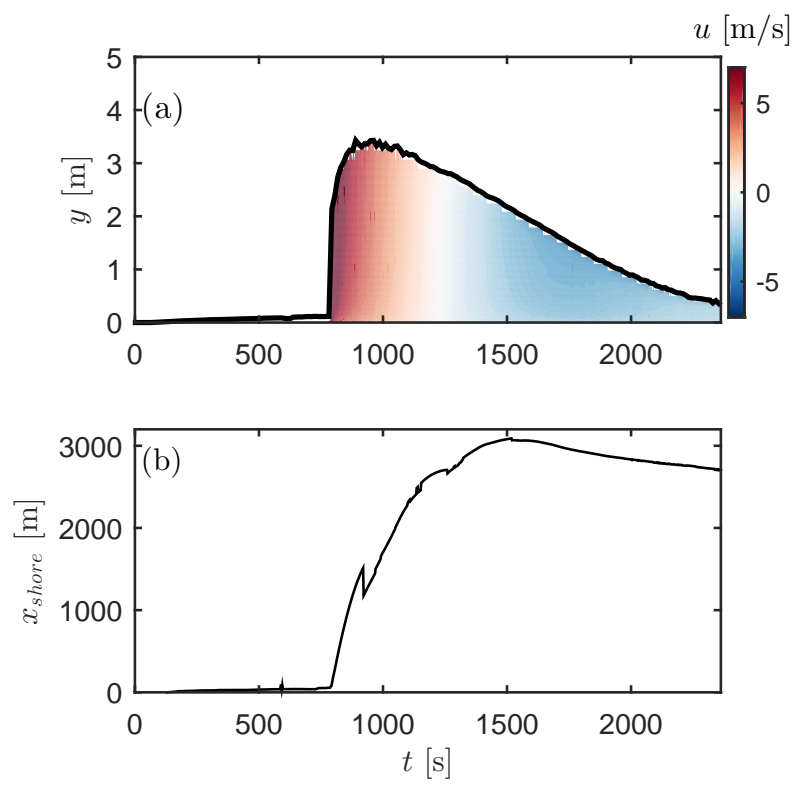

Figure 19: Results for case S500 showing (a) Velocities and surface elevations at $x=0$, (b) the horizontal position of the shoreline.

and velocities are shown at the original shoreline $(x=0 \mathrm{~m})$. Here it can be seen that for the first $12 \mathrm{~min}(720 \mathrm{~s})$, only small increases in water depth are seen, but then in $6 \mathrm{~s}$ the depth suddenly increases to approximately 2 $\mathrm{m}$, before gradually increasing to a maximum of $4 \mathrm{~m}$. From the figure it can also be seen that the milder slope, compared to case S100 (Figure 17), causes the duration over which the shore is inundated to be substantially longer. The total inundation is approximately $3 \mathrm{~km}$ in this case (Figure 18d), which is around twice the inundation distance from case S100. From the temporal development of the shoreline, shown in Figure 19b, it can be gathered that the fastest inundation speed (averaged over a minute) occurs from $t=792-852 \mathrm{~s}$, and results in an inundation speed of approximately $13.8 \mathrm{~m} / \mathrm{s}(49.7 \mathrm{~km} / \mathrm{h}=30.9 \mathrm{mi} / \mathrm{h})$, very similar to the previous case (S100) running up as a breaking bore. Obviously, this tsunami could also not be outrun.

\subsection{Undular bore}

As none of the cases with the initial set-up, with the flat part of the domain being one wave length long, resulted in an undular bore reaching all the way to the coast, an additional simulation has been made (S030L). This 
simulation entailed the single wave running onto a slope of $S=1 / 30$, but with the flat part of the domain being two wave lengths long instead of one, and with the initial tsunami positioned an entire wave length away from the shore. This was done as the formation of undular bores is dependent on the propagation distance in relatively shallow water, as highlighted by Madsen et al. (2008), among others.

Figure 20 shows surface elevations and velocities from case S030L at different times. In Figure 20a the initial wave can be seen, positioned now further away from the coast. While propagating an undular bore evolves at the front of the tsunami as seen in Figure 20b. The undular bore keeps growing with more and more individual waves forming as shown in Figure $20 \mathrm{c}$ and in the zoom in Figure 20e. While shoaling these waves, similar to the previous case S500, steepen and break, as shown in Figure 20d,f. However, due to the steeper slope (1/30 relative to $1 / 500$, see Figure 20 vs. Figure 18) the individual waves do not lose all their energy while breaking and survive all the way to the shore as seen in Figure $20 \mathrm{f}$.

The shorter waves riding in front of the tsunami have been given much importance in the past, and the appearance of these is probably one of the reasons why solitary waves have often been used to study tsunamis in the past, despite the previous mentioned scaling issues. To discuss the importance of these shorter waves relative to the bulk tsunami, we will now compare directly case S030 with S030L. These cases have the same initial wave form and are running up the same slope, but have propagated different distances before reaching the slope. Figure 21 shows surface elevations at two different times for S030 and S030L, with the time indicated by $t^{*}=t-t_{p}$, where $t_{p}$ is the time where the maximum inundation distance is reached. At the first instant, the wave is approaching the shore. In Figure 21a the wave has steepened slightly compared to the initial single wave, whereas the undular bore is clearly visible in Figure 21b. At the second instant shown the tsunamis are at their respective maximum run-up. Despite the difference in the approaching wave, it can be seen that the final run-up heights of the two cases are very similar.

Another interesting comparison is the inundation speed of the two cases. Figure 22 shows the temporal evolution of the shoreline for cases S030 and S030L. From this figure it can clearly be seen that the initial inundation speed of case S030L is significantly larger (approximately $10 \mathrm{~m} / \mathrm{s}$ versus 1 $\mathrm{m} / \mathrm{s}$ ), but overall the inundation speed and general process in both cases are very similar. For case S030 the largest inundation speed over a minute is 6.1 $\mathrm{m} / \mathrm{s}(22.1 \mathrm{~km} / \mathrm{h}=13.7 \mathrm{mi} / \mathrm{h})$ and for case S030L it is only slightly larger, namely $8.3 \mathrm{~m} / \mathrm{s}(29.9 \mathrm{~km} / \mathrm{h}=18.6 \mathrm{mi} / \mathrm{h})$, and is due to initial inundation 

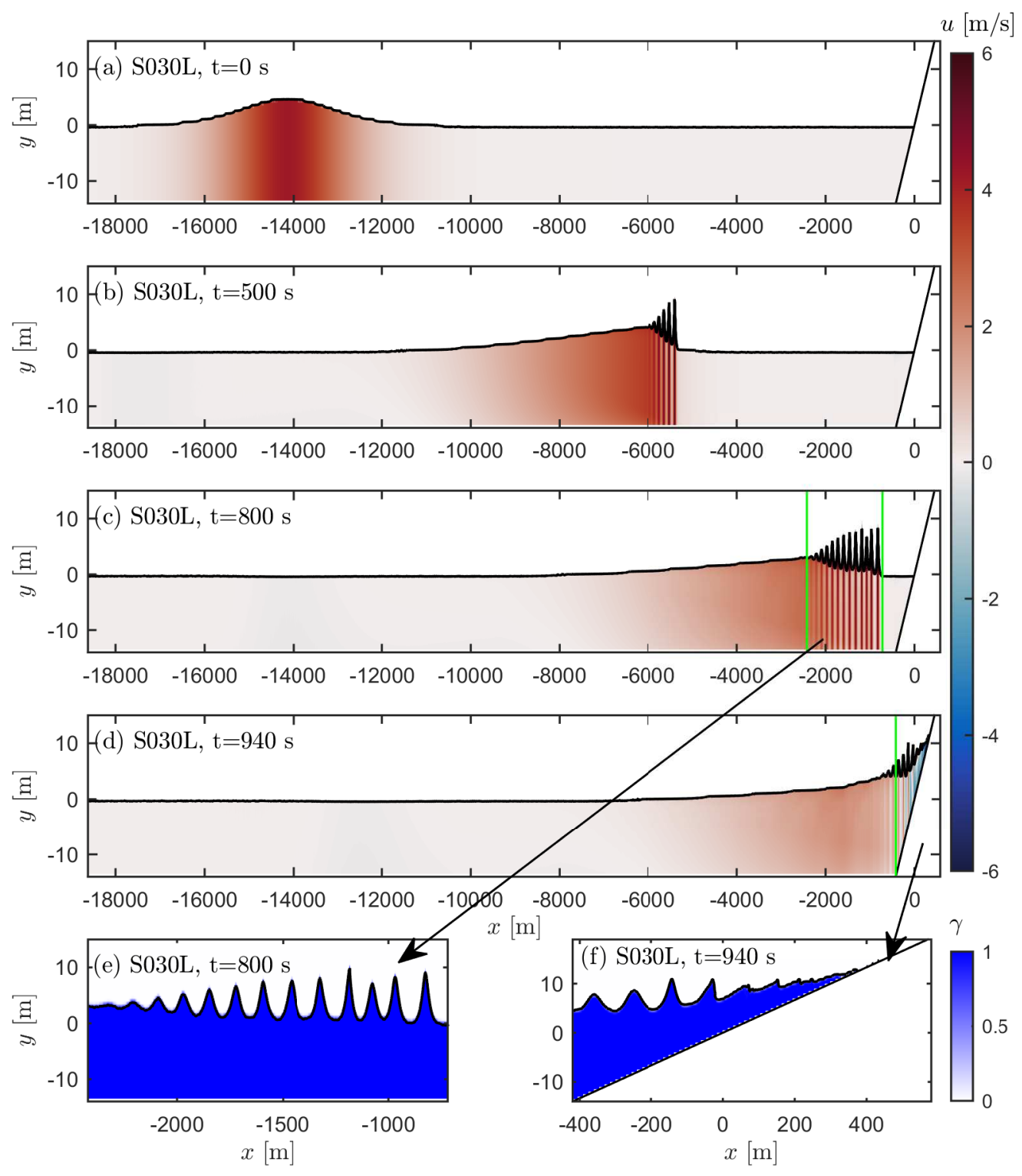

$x[\mathrm{~m}]$

Figure 20: Surface elevation and velocities of S30L at different times. Note that this figure is not to scale.

793 of the very steep undular bore front. It is worth noting, that despite not 794 breaking, the inundation speed of case S030 is substantially larger than 

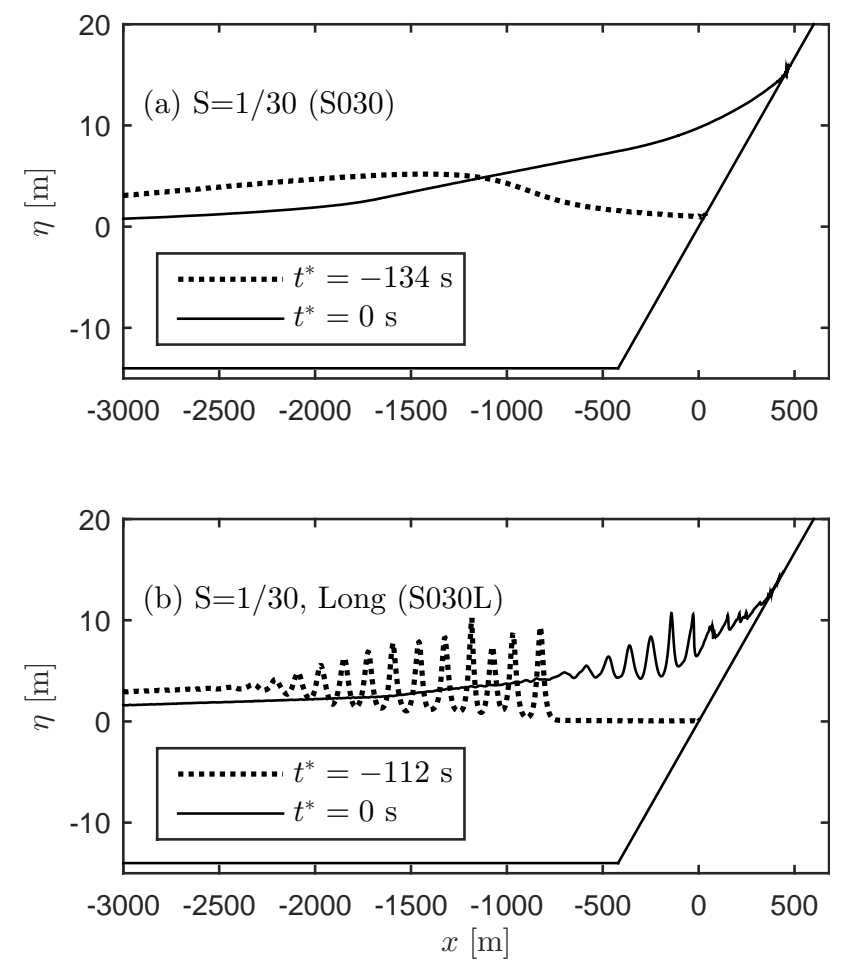

Figure 21: Comparison of run-up of single waves on a $S=1 / 30$ slope at different times.

that of case S005, but still also significantly lower than cases running up as breaking bores.

The similar run-up height and inundation speed of these two cases indicates that the bulk tsunami is much more important than the relatively shorter waves riding on top of it. This point was also previously hypothesized by Madsen et al. (2008) and Madsen and Schäffer (2010), but is more clearly and directly demonstrated and confirmed in the present fully-resolved CFD simulations. Photographs of the tsunami events show undular bores on the tsunami front without (very clearly) showing the main and much longer tsunami wave. This is natural due to the long wave length, but can result in too much importance given to the shorter waves. To illustrate this, Figure 23 shows the undular bore seen from the side (Figure 23a) and from a perspective view (Figure 23b). This illustration is very similar to one shown in Madsen et al. (2008), but it raises an important point which needs to be emphasized. When seen from the side, it can clearly be seen that front waves are riding on a much longer main wave. However, when looking from 


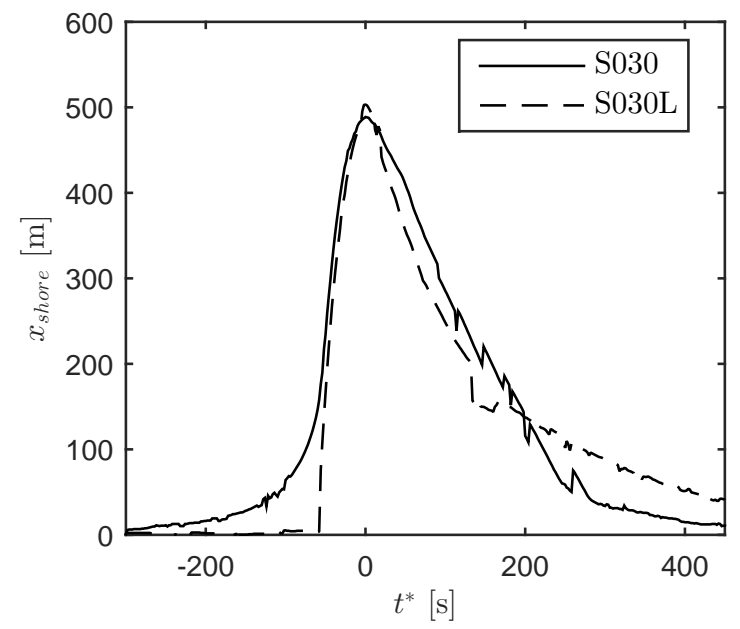

Figure 22: Development in shoreline position for cases S030 and S030L.

above, only the shorter waves are visible, which is similar to photographs and videos of real tsunami events (see e.g. Madsen et al. (2008)).

While it has been shown that the undular bore forming in front of a tsunami does not matter much for the run-up distance and inundation speed and process, it does however matter in terms of local flow velocities. These will be important when assessing forces on structures or estimating sediment transport. To illustrate this, Figure 24 shows the velocities and surface elevation of the front of the tsunami for cases S030 and S030L with the front of the tsunami having just inundated past the original shoreline $(x=0)$. It can be seen that the maximum flow velocity in case S030 is right at the tip of the inundating tsunami with velocities reaching approximately $10 \mathrm{~m} / \mathrm{s}$. The maximum flow velocities in case S030L, on the other hand, occur at the tip of the breaking short waves, with velocities here reaching up to 19 $\mathrm{m} / \mathrm{s}$. These differences in velocities may be important for the impact forces on structures, which would be expected to scale with the square of the flow velocities (see e.g. Chock, 2016). This indicates, that if attempting to model tsunami forces on structures, choosing a model which can handle dispersion and wave breaking is likely important.

\section{5. $N$-waves}

Thus far, all example run-up types have been illustrated using single waves. The same run-up types as just described (except for the undular bore, which required a longer domain to fully evolve) have also been experienced 

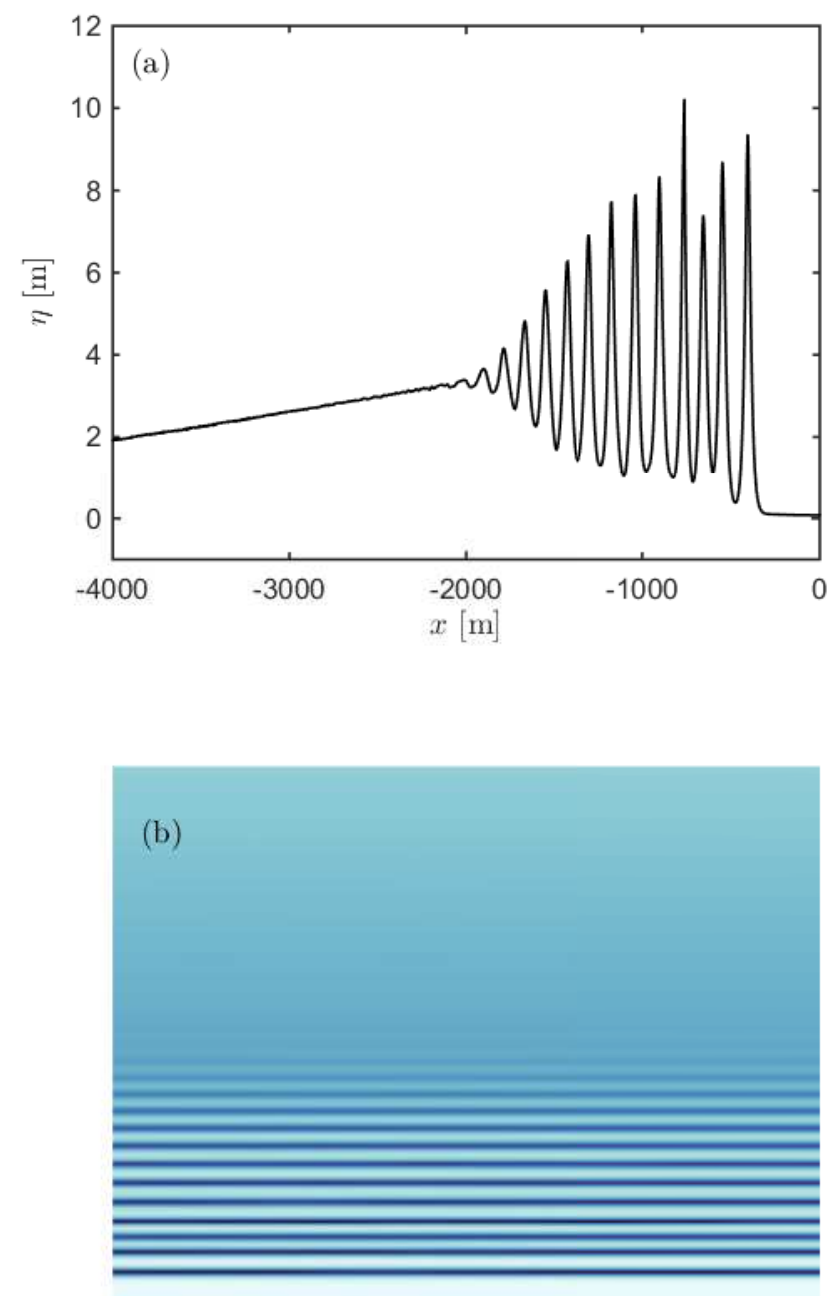

Figure 23: A (a) side looking (a) and (b) perspective view of the undular bore from case S30L

with the leading depression $\mathrm{N}$-waves. There are, however, also some distinct differences between the run-up of single waves and leading depression Nwaves. These will be discussed in what follows, by considering specifically case N100 (see again Table 1 as well as Figure 11 for this case's position on the run-up curve).

Figure 25 shows surface elevations and velocities at different instants for case N100. In contrast to the previous cases, the initial wave shown in Figure 25a now has a leading depression. The leading depression results in 


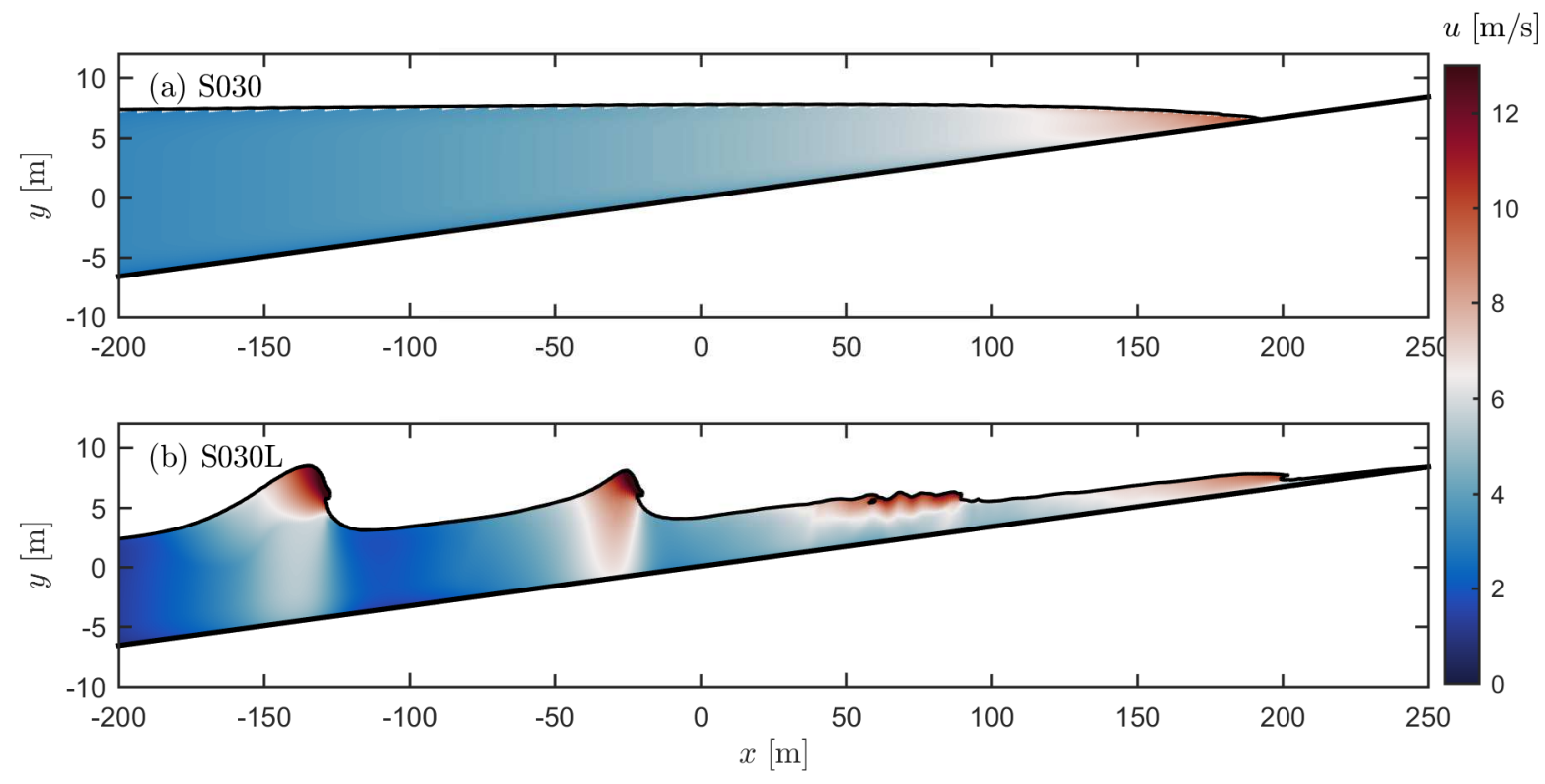

Figure 24: Surface elevations and velocities of (a) case S030 and (b) case S030L. Note that this figure is not to scale.

an initially retreating shoreline, as seen in Figure 25b. Leading depression tsunamis with retreating shorelines have been observed in many places; one of the most memorable situations is probably the tourist standing on a dry beach in Thailand with the front of the Indian Ocean tsunami approaching, see Figure 1 of Foster (2014).

Figure 25b also reveals an additional feature which is distinctively different than the previously simulated single waves, namely that the split of the front wave is not happening at the crest of the tsunami, but rather in between the trough and the crest. This can more clearly be seen in Figure 25e. A similar observation was also made in the experimental study of Matsuyama et al. (2007), where it was shown that the individual waves in some cases evolved in front of the crest of the wave. Here the waves were leading elevation sinusoidal-like waves, and thus the split occurring in front of the crest in the simulation is not due to the leading depression. The split rather occurs where the local surface elevation steepness is largest. In these simulations this was the case between the trough and crest, whereas in the experiments, due to the imperfect initial sinusoidal shape, it happened in front of the wave crest. 
Similar to case S100 the individual wave seen in Figure 25b,e cannot sustain its shape during shoaling, and breaks before reaching the slope. This wave therefore runs up as a breaking bore as shown in Figure 25c,f. As can be seen in Figure 25f, the front of the bore is only approximately $1 \mathrm{~m}$ high and fluctuations in the surface elevations are clearly visible as could be expected of breaking bores running up (see e.g. pictures from O'Donoghue et al., 2010; Johnson et al., 2016). At the same time the increase in water depth is not nearly as rapid as in cases S100 and S500 (Figures 17 and 19). This can be seen in Figure 26a where the time series of the surface elevations and velocities at $x=0 \mathrm{~m}$ are shown for case N100. Here it can clearly be seen that the depth increases much more gradually than cases S100 and S500, going from 0-3 $\mathrm{m}$ in slightly over $1 \mathrm{~min}$. The reason for this could be the leading depression, which causes the shoreline to retreat as seen in Figure 26b. The breaking tsunami front will therefore re-wet the drawn-down region prior to reaching the original shoreline at $x=0$. The appearance of this tsunami wave front is more similar to the appearance of cases S100 and S500 further inland.

The inundation speed of the present case is ultimately very similar to the single wave cases running up as a breaking bore. The maximum inundation speed (averaging over a minute) occurs at $t=500-560 \mathrm{~s}$ with a value of 11 $\mathrm{m} / \mathrm{s}(39.6 \mathrm{~km} / \mathrm{h}=24.6 \mathrm{mi} / \mathrm{h})$, indicating again that it would be impossible to outrun this tsunami run-up type.

\section{Expected occurrence of the run-up types}

In the previous subsections the run-up types have been described in detail. We will now discuss in which situations these run-up types can be expected to show up.

The first identified category, was the surging tsunami. This run-up type was only experienced in cases where the slope was very steep. In fact, it was only experienced in cases where the run-up from (28), from the analysis of Madsen and Schäffer (2010) was less than (33), corresponding to the right solid line in Figures 10 and 11. In that sense the surf-similarity parameter can be used to assess whether a surging tsunami is possible. However, as shown in case S030L, if the tsunami has propagated sufficiently far before reaching the toe of slope, an undular bore can develop. In this case the wave at the toe of slope was no longer at all described by (23). Furthermore, near the intersection of the two curves, it is not certain that a clear distinction between breaking and non-breaking cases can be made. We therefore believe it is reasonable to assume, that if the tsunami reaching the slope is linear (as 


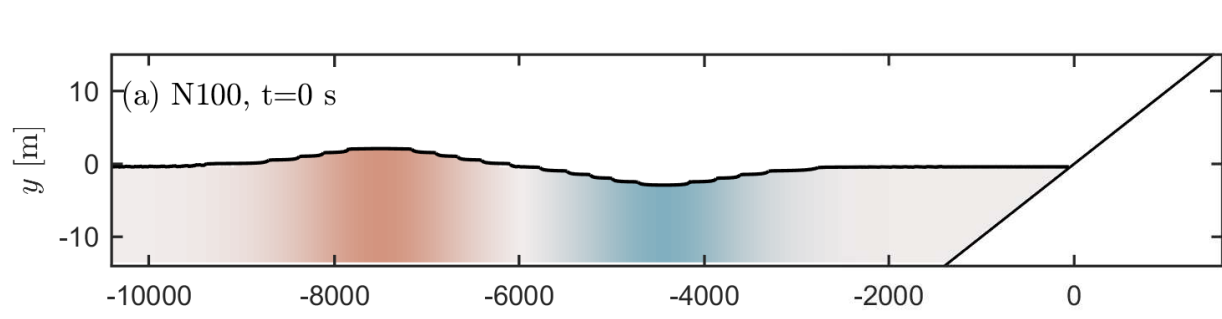

$u[\mathrm{~m} / \mathrm{s}]$
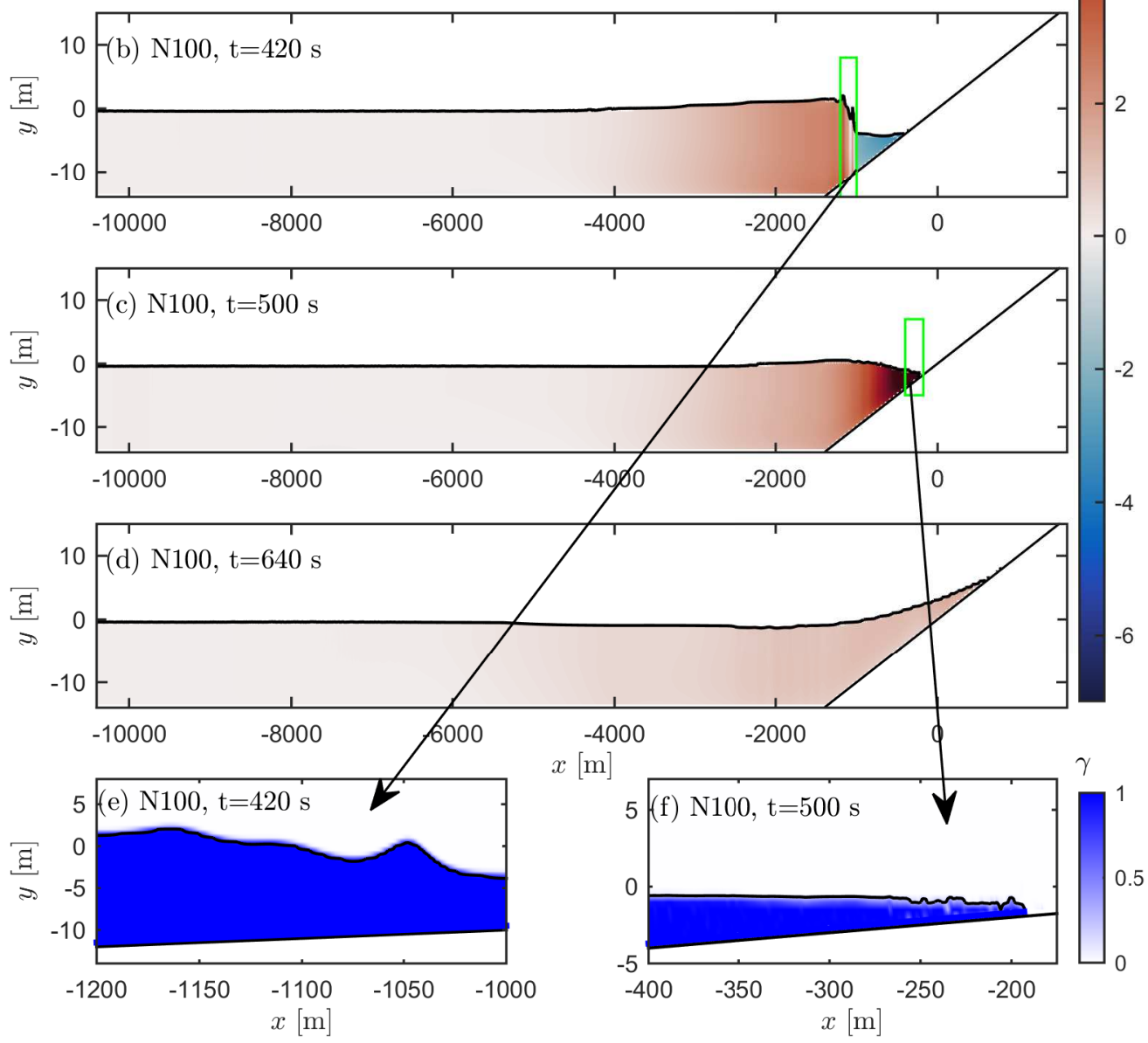

Figure 25: Surface elevation and velocities of N100 at different times. Note that this figure is not to scale.

was a pre-requisite for the Madsen and Schäffer (2010) analysis), then cases far to the right of the intersection between (28) and (33), will be surging. 

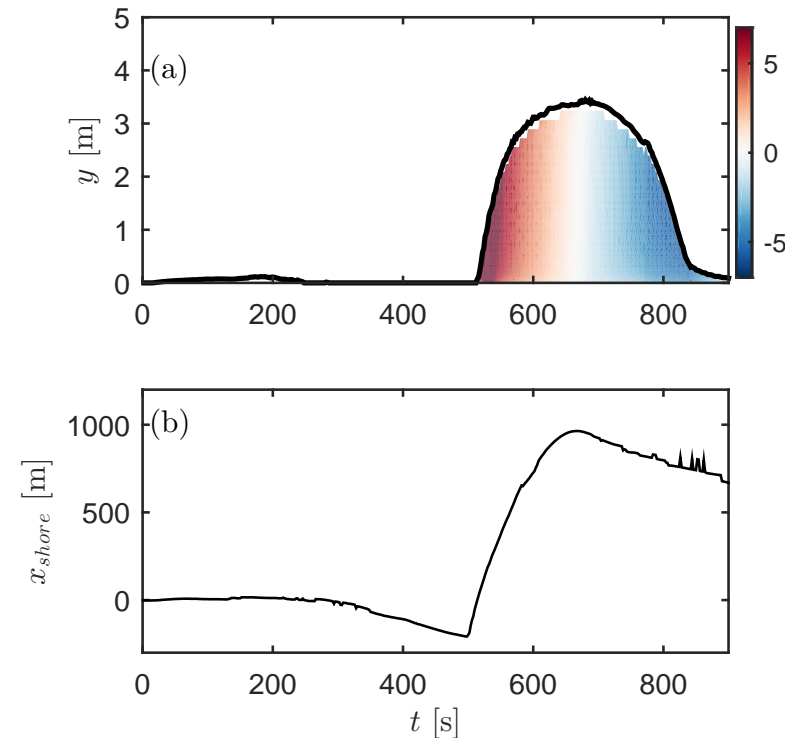

Figure 26: Results for case N100 showing (a) Velocities and surface elevations at $x=0$, (b) the horizontal position of the shoreline.

or alternatively in terms of a non-dimensional tsunami-similarity parameter

$$
\Upsilon=\frac{h_{0}^{1 / 6} \sqrt{g} S}{\Omega A_{0}^{2 / 3}} \gg\left(\chi_{\text {elev }} \pi\right)^{2 / 3} \approx 5
$$

901

902

where the sinusoidal value for $\chi_{\text {elev }}=2 \sqrt{\pi}$ has been invoked for the numerical approximation. Alternatively $\chi_{\text {elev }}$ can be found in Table 2, but since the actual wave shape cannot be known beforehand, the sinusoidal value for $\chi_{\text {elev }}$ would seem to be a reasonable approximation, as this also lies between the values for the single wave and the $\mathrm{N}$-wave. For all forthcoming calculations the sinusoidal value for $\chi_{\text {elev }}$ will be used.

The second category, the breaking bore, appeared in situations near the intersection of (28) and (33) or where $\xi<\chi_{\text {elev }}^{-2 / 3} \pi^{-1 / 6}\left(\frac{A_{0}}{h}\right)^{1 / 6}$, alternatively expressed as $\Upsilon<\left(\chi_{\text {elev }} \pi\right)^{2 / 3} \approx 5$. The latter corresponds to cases where wave breaking is predicted to be present, corresponding to the left dashed line in Figures 10 and 11. However, this will not alone make the tsunami 
run-up as a breaking bore. In situations where the slope is very mild, an undular bore can form on the front of the tsunami.

The undular bores turning into a breaking bore was only experienced in situations where $\xi \ll \chi_{\text {elev }}^{-2 / 3} \pi^{-1 / 6}\left(\frac{A_{0}}{h}\right)^{1 / 6}$ or $\Upsilon \ll\left(\chi_{\text {elev }} \pi\right)^{2 / 3} \approx 5$. For the undular bore to properly form, the slope had to be very mild, otherwise resulting in immediate breaking of the short waves riding on the front of the tsunami, due to shoaling effects.

The final category, an undular bore, has only been experienced in one case, and required the tsunami to propagate a long distance in shallow water, and subsequently run-up a steep slope. In reality tsunamis will not propagate on a flat bed before going up a constant slope region. Often it might propagate on a very mild slope before going up a steeper slope. As this is similar to the scenario of S030L, this could explain why undular bores have been observed in so many places with real geophysical tsunamis. With this kind of bed profile an undular bore developed on a very mild slope will be able to reach all the way to the shore due to the subsequent steeper slope.

The different tsunami categories exemplify the variety of ways a tsunami can appear. In research tsunamis have often been treated as breaking bores, but the classification and descriptions shown here can be used as an inspiration for alternative scenarios in experiments. An attempt to capture the undular bore followed by the much longer main tsunami wave was presented very recently in the study by Aniel-Quiroga et al. (2018b), where breakwater stability due to a tsunami attack was investigated experimentally. Here the tsunami was represented first by a series of solitary waves followed by a continuous inflow of water, to represent the main wave. As mentioned, bores have been used as tsunami representations, and the results shown in Figure 16 could be used as a full-scale inspiration. Here the breaking bore lasted approximately $500 \mathrm{~s}$, and the maximum bore velocity was close to 10 $\mathrm{m} / \mathrm{s}$. Assuming a scaling factor of 100, this would (by Froude scaling) result in a model scale bore duration of approximately 50 seconds, and a model scale bore velocity of $1 \mathrm{~m} / \mathrm{s}$. The surging tsunami has, to our knowledge, only been used in Goseberg (2013). As illustrated here, however, if considering a very steep beach, this is the most likely run-up type and representing the tsunami as a bore (though conservative) would not represent a likely tsunami scenario. Knowing the most likely tsunami scenario can be important for evacuation purposes. That breaking bores are used extensively in the literature is still understandable and justifiable, however, as these will represent a destructive scenario, which designers naturally needs to take into account. 


\section{Conclusion}

In this paper the results of 14 full scale tsunami simulations have been presented. The simulations have been performed with a RANS models, using the new stabilized $k-\omega$ model of Larsen and Fuhrman (2018b), which avoids exponential growth of the turbulent kinetic energy in a potential flow region beneath surface waves, which is characteristic of two-equation closures. The model has been first validated by comparing with surface elevations from a properly scaled tsunami experiment by Sriram et al. (2016). The model was shown to be capable of predicting the initial deformation and steepening of the wave as well as the subsequent splitting of the wave front, run-up and reflection. The model was further validated for surface elevations and bed shear stresses in the surf and swash zone by comparing to the plunging solitary wave experiments of Sumer et al. (2011). In general the model predicted both the surface elevations and the bed shear stresses well, although some differences were seen around the hydraulic jump during run-down, as well as for the bed shear stresses at the air/water/bed interface.

Using single waves and $\mathrm{N}$-waves as generic tsunami wave forms, simulations were performed of full-scale tsunamis propagating on a flat bed before running up a constant slope. The modelled run-up heights and inundation speeds for both the single waves and the N-waves were shown to compare reasonably well with the analytical expression by Madsen and Schäffer (2010) in cases where breaking would not be expected to occur. In cases where breaking could be expected to be present, the analytical solution underestimated the run-up height and inundation speed, and the expression from Hunt (1959) for the run-up height, as well as a newly proposed expression for the inundation speed, gave better estimations. The overall good comparison between analytical expression and the modelled run-up heights indicates that the combined non-breaking expressions of Madsen and Schäffer (2010) and the empirical breaking expressions from Hunt (1959) and (35) are suitable as first estimates of the run-up height and inundation speeds even in situations were the wave is non-linear at the slope, and in situations where waves break.

It has been demonstrated that, despite identical initial waves, the time series of surface elevations at the toe of the slope can be quite different for varying slopes due to the long tsunamis waves being reflected. It has been emphasized that this can pose a challenge in identifying incoming and reflected wave signals, even for what appears to be the leading wave.

Three previously defined run-up types were identified in the simulations, and their characteristics were described. Additionally a fourth type was 
identified and described. It was shown that the tsunami can appear as: (1) surging, (2) a breaking bore, (3) an "undular bore evolving into a breaking bore" and finally (4) an undular bore. In the surging scenarios the surface elevations are essentially horizontal and the inundation speeds are generally low. Furthermore, these case are characterized by full reflection from the beach, resulting in a standing wave, causing a phase shift between the maximum surface elevation and flow velocity. The surging tsunami would primarily occur in situations where the slope was sufficiently steep to be felt more or less as a vertical wall. If the tsunami is linear at the toe of the slope, the simulated results indicate that cases clearly predicted to be nonbreaking by the analytical method of Madsen and Schäffer (2010) would be surging.

On milder slopes, the tsunami steepened significantly, and the wave front split into shorter waves. In most situations these waves broke almost immediately, turning the whole tsunami into a breaking bore. In some situations more and more short waves developed, turning the front of the tsunami into an undular bore which sometimes broke before reaching the shore, and in a single case survived all the way to the shore.

It has been shown that the shorter waves of the undular bores could appear at the crest of the tsunami, as well as of the front of the crest depending on the local surface elevation steepness. It was further shown that these shorter waves had little impact on the run-up height and inundation speed, confirming previous hypothesis made by Madsen et al. (2008). They were, however, shown to be important in relation to local flow velocities, which have been demonstrated to be significantly higher when shorter waves were present.

It is hoped that the present paper will shed light on, in general, how tsunamis run-up, and from this understanding contribute to improved hazard assessment.

\section{Acknowledgements}

The authors acknowledge support from the European Union project ASTARTE-Assessment, Strategy And Risk Reduction for Tsunamis in Europe, Grant no. 603839 (FP7-ENV-2013.6.4-3). The authors likewise acknowledge financial support from the Independent Research Fund Denmark project SWASH: Simulating WAve Surf-zone Hydrodynamics and sea bed morphology, Grant no. 8022-00137B. The authors finally acknowledge Dr. V. Sriram for providing the data used for comparison in Figure 2. 


\section{References}

Aniel-Quiroga, I., Quetzalcoatl, O., Gonzalez, M., Guillou, L., 2018a. Tsunami run-up estimation based on a hybrid numerical flume and a parameterization of real topobathymetric profiles. Nat. Haz. Earth Sys. Sci. 18 (5), 1469-1491.

Aniel-Quiroga, I., Vidal, C., Lara, J. L., Gonzales, M., Sainz, A., 2018b. Stability of rubble-mound breakwaters under tsunami first impact and overflow based on laboratory experiments. Coast. Eng. 135, 39-54.

ASCE, 2016. Minimum design loads for buildings and other structures. ASCE/SEI (ASCE/Structural Engineering Institute). ASCE/SEI 7-16.

Baykal, C., Sumer, B. M., Fuhrman, D. R., Jacobsen, N. G., Fredsøe, J., 2015. Numerical investigation of flow and scour around a vertical circular cylinder. Phil. Trans. Roy. Soc. A 373, article no. 20140104.

Bayraktar, D., Ahmad, J., Larsen, B. E., Carstensen, S., Fuhrman, D. R., 2016. Experimental and numerical study of wave-induced backfilling beneath submarine pipelines. Coast. Eng. 118, 63-75.

Berberovic, E., van Hinsberg, N. P., Jakirlic, S., Roisman, I. V., Tropea, C., 2009. Drop impact onto a liquid layer of finite thickness: Dynamics of the cavity evolution. Phys. Rev. E 79 (3), article no. 036306.

Biscarini, C., 2010. Computational fluid dynamics modelling of landslide generated water waves. Landslides 7 (2), 117-124.

Brown, S. A., Greaves, D. M., Magar, V., Conley, D. C., 2016. Evaluation of turbulence closure models under spilling and plunging breakers in the surf zone. Coast. Eng. 114, 177-193.

Carrier, G. F., Greenspan, H. P., 1958. Water waves of finite amplitude on a sloping beach. J. Fluid Mech. 4, 97-109.

Cebeci, T., Chang, K. C., 1978. Calculation of incompressible rough-wall boundary-layer flows. AIAA J. 16, 730-735.

Chen, J., Huang, Z., Jiang, C., Deng, B., Long, Y., 2012. An experimental study of changes of beach profile and mean grain size caused by tsunamilike waves. J. Coast. Res. 28 (5), 1303-1312.

Chock, G. Y. K., 2016. Design for tsunami loads and effects in the asce 7-16 standard. J. of Strut. Eng. 142 (11), 04016093. 
Derschum, C., Nistor, I., Stolle, J., Goseberg, N., 2018. Debris impact under extreme hydrodynamic conditions part 1: Hydrodynamics and impact geometry. Coast. Eng. 141, 24-35.

Deshpande, S. S., Anumolu, L., Trujillo, M. F., 2012. Evaluating the performance of the two-phase flow solver interFoam. Comput. Sci. Discov. 5 (1), article no. 014016.

Drähne, U., Goseberg, N., Vater, S., Beisiegel, N., Behrens, J., 2016. An experimental and numerical study of long wave run-up on a plane beach. J. Marine Sci. Eng. 4 (1), 1 (23 pp.).

Foster, P., 2014. Boxing day tsunami, 10 years on: 'the water came my family is gone. The Telegraph, 26 December.

Fuhrman, D. R., Baykal, C., Sumer, B. M., Jacobsen, N. G., Fredsoe, J., 2014. Numerical simulation of wave-induced scour and backfilling processes beneath submarine pipelines. Coast. Eng. 94, 10-22.

Fuhrman, D. R., Madsen, P. A., 2009. Tsunami generation, propagation, and run-up with a high-order boussinesq model. Coast. Eng. 56 (7), 747758 .

Glimsdal, S., Pedersen, G. K., Harbitz, C. B., Lovholt, F., 2013. Dispersion of tsunamis: does it really matter? Nat. Haz. Earth Sys. Sci. 13 (6), $1507-1526$.

Goseberg, N., 2013. Reduction of maximum tsunami run-up due to the interaction with beachfront development - application of single sinusoidal waves. Nat. Haz. Earth Sys. Sci. 13 (11), 2991-3010.

Goseberg, N., Stolle, J., Nistor, I., Shibayama, T., 2016. Experimental analysis of debris motion due the obstruction from fixed obstacles in tsunamilike flow conditions. Coast. Eng. 118, 35-49.

Goseberg, N., Wurpts, A., Schlurmann, T., 2013. Laboratory-scale generation of tsunami and long waves. Coast. Eng. 79, 57-74.

Grilli, S. T., Harris, J. C., Bakhsh, T. S. T., Masterlark, T. L., Kyriakopoulos, C., Kirby, J. T., Shi, F., 2013. Numerical simulation of the 2011 Tohoku tsunami based on a new transient FEM co-seismic source: Comparison to far- and near-field observations. Pure Appl. Geophys. 170 (6-8), $1333-1359$. 
Grue, J., Pelinovsky, E. N., Fructus, D., Talipova, T., Kharif, C., 2008. Formation of undular bores and solitary waves in the strait of Malacca caused by the 26 December 2004 Indian Ocean tsunami. J. Geophys. Res. 113 (C5), C05008.

Horrillo, J., Kowalik, Z., Shigihara, Y., 2006. Wave dispersion study in the Indian Ocean tsunami of December 26, 2004. Sci. of Tsunami Haz. 25, $42-63$.

Hunt, I. A., 1959. Design of seawalls and breakwaters. J. Waterw. Harbors Division ASCE 85, 123-152.

Jacobsen, N. G., Fuhrman, D. R., Fredsøe, J., 2012. A wave generation toolbox for the open-source CFD library: OpenFOAM (R). Int. J. Numer. Meth. Fluids 70, 1073-1088.

Jiang, C., Chen, J., Yao, Y., Liu, J., Deng, Y., 2015. Study on threshold motion of sediment and bedload transport by tsunami waves. Ocean Eng. 100, 97-106.

Johnson, J. P. L., Delbecq, K., Kim, W., Mohrig, D., 2016. Experimental tsunami deposits: Linking hydrodynamics to sediment entrainment, advection lengths and downstream fining. Geomorphology 253, 478-490.

Kawai, H., Satoh, M., Kawaguchi, K., Seki, K., 2013. Characteristics of the 2011 Tohoku tsunuami waveform acquired around Japan by NOWPHAS equipment. Coast. Eng. J. 55 (3), 1350008.

Kim, D.-H., Lynett, P. J., 2011. Dispersive and nonhydrostatic pressure effects at the front of surge. J. Hydraul. Eng. ASCE 137 (7), 754-765.

Lacy, J. R., Rubin, D. M., Buscombe, D., 2012. Currents, drag, and sediment transport induced by a tsunami. J. Geophys. Res.- Oceans 117 (9), article no. C0928.

Larsen, B. E., 2018. Tsunami-seabed interactions. Ph.D. thesis, Technical University of Denmark, Kgs. Lyngby, Denmark.

Larsen, B. E., Arbøll, L. K., Frigaard, S., Carstensen, S., Fuhrman, D. R., 2018a. Experimental study of tsunami-induced scour around a monopile foundation. Coast. Eng. 138, 9-21.

Larsen, B. E., Fuhrman, D. R., 2018a. Full-scale CFD simulation of tsunamis. Part 2: Boundary layers and bed shear stresses. Submitted. 
Larsen, B. E., Fuhrman, D. R., 2018b. On the over-production of turbulence beneath surface waves in Reynolds-averaged Navier-Stokes models. J. Fluid Mech. 853, 419-460.

Larsen, B. E., Fuhrman, D. R., Baykal, C., Sumer, B. M., 2017. Tsunamiinduced scour around monopile foundations. Coast. Eng. 129, 36-49.

Larsen, B. E., Fuhrman, D. R., Roenby, J., 2018b. Performance of interFoam on the simulation of progressive waves. Submitted, also axiv.org. ID: 1804.01158 [physics.flu-dyn].

Larsen, B. E., Fuhrman, D. R., Sumer, B. M., 2016. Simulation of waveplus-current scour beneath submarine pipelines. J. Waterw. Port C-ASCE 142 (5), article no. 04016003.

Levin, B., Nosov, M., 2016. Physics of Tsunamis. Springer Netherlands.

Løvholt, F., Kaiser, G., Glimsdal, S., Scheele, L., Harbitz, C. B., Pedersen, G., 2012. Modeling propagation and inundation of the 11 March 2011 Tohoku tsunami. Nat. Haz. Earth Sys. Sci. 12 (4), 1017-1028.

Lynett, P., Liu, P. L.-F., 2002. A numerical study of submarine-landslidegenerated waves and run-up. Proc. R. Soc. Lond. A 458, 2885-2910.

Lynett, P., Liu, P. L.-F., 2005. A numerical study of the run-up generated by three-dimensional landslides. J. Geophys. Res. 110, C03006/1-16.

Madsen, P. A., Fuhrman, D. R., 2008. Run-up of tsunamis and long waves in terms of surf-similarity. Coast. Eng. 55, 209-223.

Madsen, P. A., Fuhrman, D. R., Schäffer, H. A., 2008. On the solitary wave paradigm for tsunamis. J. Geophys. Res. 113, article no. C12012.

Madsen, P. A., Schäffer, H. A., 2010. Analytical solutions for tsunami runup on a plane beach. J. Fluid Mech. 645, 27-57.

Madsen, P. A., Schäffer, H. A., Fuhrman, D. R., Toledo, Y., 2016. Uniform asymptotic approximations for transient waves due to an initial disturbance. J. Geophys. Res. 121 (1), 60-84.

Matsuyama, M., Ikeno, M., Sakakiyama, T., Takeda, T., 2007. A study of tsunami wave fission in an undistorted experiment. Pure Appl. Geophys. $164(2-3), 617-631$. 
Mayer, S., Madsen, P. A., 2000. Simulations of breaking waves in the surf zone using a Navier-Stokes solver. In: Proc. 25th Int. Conf. Coast. Eng. Sydney, Australia, pp. 928-941.

Montagna, F., Bellotti, G., Di Risio, M., 2011. 3D numerical modeling of landslide-generated tsunamis around a conical island. Nat. Haz. 58 (1), 591-608.

Nistor, I., Goseberg, N., Stolle, J., Mikami, T., Shibayama, T., Nakamura, R., Matsuba, S., 2017. Experimental investigations of debris dynamics over a horizontal plane. J. Waterw. Port C-ASCE 143 (3), 04016022.

O'Donoghue, T., Pokrajac, D., Hondebrink, L. J., 2010. Laboratory and numerical study of dambreak-generated swash on impermeable slopes. Coast. Eng. 57 (5), 513-530.

Park, H., Cox, D. T., Petroff, C. M., 2015. An empirical solution for tsunami run-up on compound slopes. Nat. Haz. 76 (3), 1727-1743.

Qu, K., Ren, X. Y., Kraatz, S., 2017. Numerical investigation of tsunamilike wave hydrodynamic characteristics and its comparison with solitary wave. Appl. Ocean Res. 63, 36-48.

Rossetto, T., Allsop, W., Charvet, I., Robinson, D. I., 2011. Physical modelling of tsunami using a new pneumatic wave generator. Coast. Eng. $58(6), 517-527$.

Schimmels, S., Sriram, V., Didenkulova, I., 2016. Tsunami generation in a large scale experimental facility. Coast. Eng. 110, 32-41.

Shuto, N., 1985. Nihonkai-Chubu earthquake tsunami on the north Akita coast. Coast. Eng. Japan 28, 255-264.

Sriram, V., Didenkulova, I., Sergeeva, A., Schimmels, S., 2016. Tsunami evolution and run-up in a large scale experimental facility. Coast. Eng. $111,1-12$.

Stolle, J., Derschum, C., Goseberg, N., Nistor, I., Petriu, E., 2018. Debris impact under extreme hydrodynamic conditions part 2: Impact force responses for non-rigid debris collisions. Coast. Eng. 141, 107-118.

Sumer, B. M., Sen, M. B., Karagali, I., Ceren, B., Fredsøe, J., Sottile, M., Zilioli, L., Fuhrman, D. R., 2011. Flow and sediment transport induced by a plunging solitary wave. J. Geophys. Res. 116 (1), C01008. 
1202

1203

1204

1205

1206

1207

1208

1209

1210

1211

1212

1213

1214

1215

1216

1217

1218

1219

1220

Suppasri, A., Muhari, A., Ranasinghe, P., Mas, E., Shuto, N., Imamura, F., Koshimura, S., 2012. Damage and reconstruction after the 2004 Indian Ocean tsunami and the 2011 Great East Japan tsunami. J.l Nat. Disaster Sc. 34 (1), 19-39.

Synolakis, C. E., Bernard, E. N., 2006. Tsunami science before and beyond Boxing Day 2004. Phil. Trans. Roy. Soc. Lond. A 364, 2231-2265.

TD Interesting Topics Tube, 2015. Largest and best tsunami compilation of japan tohoku eartquake 2011.

घ URL https://www.youtube.com/watch?v=S2ZOmMH4WHA, retrievedFebruary14,2018

TD Interesting Topics Tube, 2017. Giant tsunami in Miyako - final documentary - japan 2011.

4 URL https://www.youtube.com/watch?v=xtd6xUuul1s, retrievedFebruary14,2018

Tomita, T., Honda, K., Kakinuma, T., 2006. Application of Storm surge and Tsunami simulator in Oceans and Coastal areas (STOC) to tsunami analysis. In: Joint Panel Conference of the U.S.-Japan Cooperative Program in Natural Resources, , Volume 38. pp. 109-115.

Tomita, T., Takahashi, K., 2014. Simulation of tsunami accompanied by breaking short-period waves. In: Proc. 34th Int. Conf. Coast. Eng. Seoul, Korea, pp. 1-9.

van Driest, E. R., 1956. On turbulent flow near a wall. J. Aeronautical Sciences 23, 1007-1011, 1036.

Wemmenhove, R., Luppes, R., Veldman, A. E. P., Bunnik, T., 2015. Numerical simulation of hydrodynamic wave loading by a compressible two-phase flow method. Comput. Fluids 114, 218-231.

Wilcox, D. C., 2006. Turbulence Modeling for CFD, 3rd Edition. DCW Industries, Inc., La Canada, California.

Williams, I. A., Fuhrman, D. R., 2016. Numerical simulation of tsunamiscale wave boundary layers. Coast. Eng. 110, 17-31.

Yeh, H. H., 1991. Tsunami bore runup. Nat. Haz. 4 (2-3), 209-220. 